\title{
Midwives' Experiences of Caring for Women During Childbirth Who have Undergone Female Genital Mutilation:
}

\section{An Interpretative Study}

\author{
by
}

Annette Marie Garvey-Graham

\author{
A thesis submitted to the Victoria University of Wellington \\ in partial fulfilment of the \\ requirements for the degree of \\ Master of Arts (Applied) \\ in Midwifery
}

Victoria University of Wellington

2008 


\begin{abstract}
In recent years, as a result of globalisation and increased immigration from countries known to engage in Female Genital Mutilation (FGM), exposure to the results of the centuries old tradition/cultural practice of FGM Type III is becoming part of the New Zealand midwifery experience. While a wealth of information exists around the FGM procedure itself, little research has been specifically documented about the midwives' experiences of caring for women in childbirth who have undergone this procedure.
\end{abstract}

This study captures the experience of a small group of midwives, caring for women who have undergone FGM Type III, during the childbirth experience. It focuses on the feelings and experiences of the midwives during the process of labour and birth. An interpretive approach was adopted, using in-depth open-ended interviews, in order to explore, to gain insight and to understand the midwife’s experience.

The study recognises there are many different possible interpretations with midwives 'telling their story', and identifies issues that they encountered in providing care for these women. Four themes were identified in the midwife's experience: 'feeling unprepared', 'negotiating the cultural gap', 'the traumatic reality of deinfibulation' and 'tensions and paradoxes'. These reflect the journey of the midwife through their experiences and the challenges they faced.

This research proposes that midwives require further support in their theoretical and practical knowledge in caring for women who have undergone FGM Type III. It also highlights the lack of structured support and information that surrounds their care.

Keywords: Circumcision; Female; Female Genital Mutilation (FGM); Midwife; Narrative. 


\section{Acknowledgements}

To my beautiful and precious Mother and Father, they share the success of this thesis. I thank God for you both and the wonderful life values you instilled in me that continue to inspire each day. To my amazing brothers, for being there, reminding me to keep a sense of perspective and always making me smile. To my inner circle of dear friends, thank you for your support and encouragement.

Thank you to my supervisor, Dr Joan Skinner, for a journey that has been challenging and provided much learning about writing, and trusting the research process.

While this study has my name on it, I wish to acknowledge the many other voices that have participated in the dialogues of this journey. This thesis would not have been possible without the support of my research participants.

Finally, last but by no means least I wish to thank Michael. You are my blessing. Thank you does not seem enough! You consistently believe in me and embrace my aspirations. Your deep love, support and encouragement throughout this journey has kept me steady in the wind. 


\section{Table of Contents}

Title page $\quad$ i

Abstract ii

Acknowledgements iii

Table of Contents

Chapter One: Introduction and Orientation to the Study 1

Study Impetus 1

A story from my practice $\quad 2$

Research Aim and Objectives 3

Structure of the Thesis 4

Chapter Two: Setting The Context 6

What is Female Genital Mutilation? 6

Health complications of FGM Type III 6

Deinfibulation $\quad 7$

Legal status $\quad 8$

Human Rights $\quad 10$

FGM and the Midwife 12

FGM based literature in the U.K. 14

FGM based literature in New Zealand 15

The Nature of the Midwifery Relationship 16

$\begin{array}{ll}\text { Summary } & 17\end{array}$

Chapter Three: Research Design, Methods and Processes 19

Qualitative Research 19

Narrative inquiry 19

Methods and Processes $\quad 22$

Study location $\quad 22$

Selection criteria and participant numbers $\quad 22$

Recruitment process 23

Research participants 24

Data Collection 25

The interviews 25

Data analysis 27

Ethical considerations $\quad 29$

Research trustworthiness 30

Limitations of the study 31

Summary 32

Chapter Four: The Findings $\quad 34$

Data Analysis - The True Song 34

The Themes $\quad 37$

Introduction of the themes 38

Feeling unprepared 38

Negotiating the cultural gap 39

The traumatic reality of deinfibulation 40

Tensions and paradoxes 43 
Chapter Five: Discussion $\quad 47$

The Knowledge Gap $\quad 47$

Developing Culturally Safe Care $\quad 50$

Undoing the harm $\quad 52$

Ignorance or avoidance $\quad 52$

The medical argument against posterior episiotomy 52

The ethical argument against posterior episiotomy 53

The re-traumatisation $\quad 54$

The legal framework $\quad 55$

Filling the gap 56

Cultural Conflict $\quad 57$

Describing the cultural context for FGM 58

Autonomy for the woman $\quad 59$

Beneficence and non-maleficence 60

$\begin{array}{ll}\text { Summary } & 63\end{array}$

Chapter Six: Conclusion and Recommendations $\quad 64$

Meeting the research aims $\quad 64$

Recommendations 66

Further research 68

Final comments $\quad 68$

\section{Appendices}

$\begin{array}{ll}\text { A Information to participate } & 70\end{array}$

B Consent form $\quad 73$

C Transcriber confidentiality form $\quad 74$

D Return of transcript explanation $\quad 75$

E Release of transcripts 76

$\begin{array}{lll}\text { F } & \text { Ethical approval memorandum } & 77\end{array}$

$\begin{array}{ll}\text { References } & 78\end{array}$ 


\section{Chapter One: Introduction and Orientation to The Study}

Globally, over 130 million girls and women have undergone some form of Female Genital Mutilation (FGM) and at least 2 million girls are at risk of being subjected to these practices each year (Toubia, 1995). The World Health Organization (1997) defines female genital mutilation as: "all procedures involving partial or total removal of the external female genitalia or other injury to the female genital organs whether for cultural or other non-therapeutic purposes" (p.3). Infibulation which is "excision of part or all of the external genitalia, and involves the ...stitching/narrowing of the vaginal opening” is a consequence of the more severe forms of FGM (WHO, 1997, p.5).

In recent years, as a result of globalisation, immigration and the settlement of refugees, exposure to the results of the centuries-old tradition/cultural practice of Female Genital Mutilation is becoming part of the New Zealand midwifery experience. However, little is known nationally and internationally about how midwives care for women, who have experienced FGM, during childbirth. Although FGM is performed to varying degrees, this study investigates the experience of caring for women with Female Genital Mutilation Type III. This type of FGM narrows the vaginal opening and is most likely to cause obstetric complications requiring the direct intervention by midwives to facilitate childbirth (WHO, 2001). This thesis focuses on that experience from the midwife's perspective, reflecting on the challenges and obstacles that the midwife encounters whilst caring for women with FGM within the New Zealand context. This research is an interpretive study of the experience of midwives caring for women during the childbirth process, who have undergone Female Genital Mutilation Type III.

\section{Study Impetus}

During extensive travels throughout developing countries, my first exposure to Female Genital Mutilation (FGM) Type III occurred. The impetus for this study came from within the context of my midwifery practice whilst working in Riyadh, Saudi Arabia, where many of the migrants had come from countries where Female Genital Mutilation is still performed. I had the privilege to facilitate the birth experience of a 
number of women who had undergone Female Genital Mutilation earlier in their lives. At that time, my involvement with these women was limited to midwifery and cultural practices of Middle Eastern society. In these countries the majority of women did not have antenatal care and therefore often presented at birthing suite with pregnancy problems, leading to obstetric complications. This would further be compounded if the women had undergone FGM. The situation would frequently occur in that once a woman had been deinfibulated by me, (the 'undoing' of the infibulated state), an obstetrician would repair the 'harm' caused by the 'undoing' of her infibulated state, by reinfibulating. Although constrained by the environment at the time, my internal dialogue questioned the necessity of reinfibulation, which seemed contraindicated by my knowledge. Yet this seemed the norm, readily practiced by the obstetricians and not unexpected by the women encountered. I felt I was missing parts of the puzzle, I needed to gain an understanding as to why the initial act was performed and then why someone would reinstate a condition that seemed to be against any health benefit for the woman.

\section{A story from my practice}

I had only worked a few days in my new position as a staff midwife, in what was a busy birthing suite in Riyadh, Saudi Arabia. On this day I had five hours remaining from a busy twelve-hour shift. I was mentally and physically exhausted, as I had just facilitated a long and difficult birth, when a woman arrived and asked for my assistance with her daughter. Her daughter was clearly in established labour. I hastily transferred her to the birthing room where she immediately climbed onto the bed and began to push.

I gained her consent to lift her clothing to see if I could see baby approaching. I was now confronted with something that I had only read about. She had clearly undergone infibulation. I was shocked. I found it a harrowing experience and was not prepared to deal with this. At that moment, I forgot my professional demeanour. What was I supposed to do? Collecting myself and remembering my role, I started to think like a midwife. How was baby going to come out of that narrow remnant of an opening? The perineum was stretching well! I had a limited knowledge base, but no clinical practice experience. I drew on what knowledge I had and deinfibulated, cutting 
through scar tissue to widen the vaginal opening. Fortunately the birth went well, with a safe outcome for mother and baby. At this time and this location it was delivery suite policy that after the birth, an obstetrician would reinfibulate. I felt some relief that the obstetrician would resolve the harm I felt I caused by my 'undoing' of her infibulated state.

I wish that my first exposure to this practice had not left me in such disbelief, shock and sadness, and that my professional demeanour had not been betrayed by my naivety. From that day forward I vowed to increase my knowledge about FGM and explore my own feelings with regard the consequences of the act. McCleary (1994) states, "one does not have to agree with it [FGM] but should understand the medical consequences upon a woman's health, in order that care is improved” (p. 223).

My own experience with caring for women with FGM Type III prompted this research and coloured my subsequent interest in, and exploration of the topic. My experience was embedded within my own educational context, as I trained in the U.K. as a registered nurse and midwife. I consider, however, that many of the issues and concerns that I encountered were likely to be encountered by others. It was this focus that influenced the aims of this research.

\section{Research Aim and Objectives}

The aim of this research is to explore the experience of midwives working with women during the childbirth process, who have undergone Female Genital Mutilation Type III. It is anticipated that if midwives recount their stories of being in this situation, analysis of these experiences will illuminate any dilemmas that might exist and help in addressing these dilemmas. The objectives of the research are to:

- Capture the stories of a small group of midwives who have cared for women, during the childbirth experience, who have undergone Female Genital Mutilation (FGM) Type III. 
- Uncover and explore the issues that are contained in the midwives' stories in order to illuminate their experiences encountered in providing care for these women.

The International Confederation of Midwives believes that in every culture there exists the possibility of harmful traditions imposed on young girls and women, and is therefore committed to working in partnership with women to change these harmful practices (1999). Although it is not intended to diminish the importance of that work, this research is not an attempt to address the ethical issues of FGM, but rather to respond to the issues encountered by the midwives when caring for women who have FGM Type III.

The uniqueness of autonomous and independent midwifery practice within New Zealand, offers an opportunity for midwives to steer head the formulation of evidence-based guidelines and protocols relating to midwives' care and the management of women during the childbirth experience who have undergone FGM Type III. It is intended that this study, by focussing on the experience of midwives who have been in this situation, will generate knowledge for practice from practice. It is hoped that this knowledge will inform midwives, nationally and internationally, health professionals, legislators and perhaps ultimately assist the women themselves.

\section{Structure of the Thesis}

Chapter Two: Setting the Context begins by defining what FGM is and the health complications of the act. It identifies the legal status of the act of FGM within New Zealand and international law. A review of the literature pertaining to FGM within the U.K. and New Zealand context is explored and discussed at length. The chapter ends with background discussion around the privileged relationship of the midwife and woman in the context of midwifery practice within New Zealand. Chapter Three describes the research approach, design and processes utilised for data collection and analysis. Ethical considerations and how they were addressed with the research participants are highlighted. Discussion into how research trustworthiness was ensured, highlighting the sign-posts for qualitative research is discussed prior to the 
limitations of the study. In Chapter Four, the findings of the research are presented, by way of a short story that distils the essence of the experiences recounted by the midwives in their interviews. Four key themes emerge from the midwives telling their story and are discussed. Chapter 5 adds further clarity to the understanding of the midwives stories, by identifying two key threads that are interwoven within the four themes. These are further explored and uncover questions that have implications for midwifery practice. Chapter 6 concludes the study by revisiting the aims of the study and the research question in light of the findings, and proposes recommendations for practice and future research. 


\section{Chapter Two: Setting The Context}

The field of interest in this research lies beyond the initial act of FGM and focuses on the experience of those who are confronted by the procedure, in a most intimate and immediate fashion, while being removed from the cultural paradigm in which it occurred. However, in order to understand the implications of this research some understanding of the nature of FGM Type III is required. This chapter provides an outline of the nature of FGM, considers recent literature around the topic generally and scrutinises more closely the literature related to the experience of the midwife while dealing with this phenomenon.

\section{What is Female Genital Mutilation?}

The World Health Organization defines and classifies Female Genital Mutilation into four categories. This study focuses on the consequences of the most severe form of this practice ‘infibulation' or 'pharaonic' circumcision, which is 'excision of part or all of the external genitalia and stitching or narrowing of the vaginal opening', and is known as FGM Type III (WHO, 1997 p.5). According to Jordan (1994) this is similar to a vulvectomy. Midwives caring for women with FGM Type III must address the complications FGM causes in childbirth.

The term Female Circumcision has been posited as an alternative to FGM and is used to avoid the prejudicial connotations of mutilation. To refer to the procedure as female circumcision is anatomically inaccurate and obfuscates the nature of the act behind a veil of respectability.

\section{Health complications of FGM Type III}

Within the New Zealand context, although ostensibly caring for women through the childbearing process who have undergone FGM in childhood, the midwife will also encounter the long-term health complications that the procedure entails. The likely health implications are well documented and include; permanent pain in the vulval area due to nerve damage, development of cysts, obstructed blood flow resulting in 
chronic periods, pelvic infections and primary infertility, obstructed urine flow resulting in recurrent urine infections, renal damage and potentially renal failure (Rawlings-Anderson \& Cameron, 2000). Further there is reliable evidence about its harmful effects on gynaecological and reproductive outcomes and the increased chance of maternal and child mortality (Cameron \& Rawlings-Anderson, 2001). It comes as no surprise therefore, that in terms of their physical health, it is considered better for the women not to be infibulated.

\section{Deinfibulation}

Deinfibulation is the process by which the infibulated introitus is enlarged. In many societies deinfibulation is generally carried out before marriage, as it involves enlarging the introitus, which facilitates sexual intercourse (Cameron and RawlingsAnderson, 2001). Justification for deinfibulation was offered by Dahlen, Nanayakkara and Bullivant (1999), who stated it was required to avoid the complications of '... obstructed labour, large posterior or bilateral episiotomy, third and fourth degree tears and routine caesarean sections' (p.13). These justifications also relate to potential risk factors for both mother and baby during birth. The mother is likely to suffer a prolonged second stage of labour caused by excessive inelastic scar tissue causing obstruction, leading to possible uterine rupture. Within the context of this research, however, the primary intent behind deinfibulation is the creation of an opening of sufficient size to enable the safe delivery of the baby. According to Denholm and Jama (1998) 'almost all primigravidas will need to be deinfibulated to allow for the delivery of the foetal head' (p.27).

Much of the literature examined did not mention or only alluded to the procedure of deinfibulation. A clear understanding of how to perform the procedure is frequently absent. However, Dahlen, Nanayakkara and Bullivant (1999) give detailed recommendations on appropriate antenatal care and possible complications as a result of FGM, intrapartum care, performing deinfibulation and its repair. Their article includes clear and useful diagrams. Although the article is not specifically targeted to midwives, it is a useful and detailed reference. They state that deinfibulation is fundamental to the care of women who have FGM Type III, as part of the 
childbirthing process and within the context of childbirth, this should ideally occur antenatally, between 20 to 28 weeks.

Newman (1996) also provides a detailed explanation of the procedure. She states "the incision is made, by placing one finger on the introitus and cutting upwards until the urethral meatus is visible” (p.22). Deinfibulation should not be considered a reversal of infibulation, since excised external genitalia cannot be replaced; rather deinfibulation is a sequel to infibulation and is required to facilitate a safe delivery while reducing possible medical complications.

\section{Legal Status}

In 1985 the United Kingdom introduced the Prohibition of Female Circumcision Act. Following a parliamentary hearing, the All Party Parliamentary Group on Population Development and Reproductive Health published a report in 2000 recommending amendments to this Act to prevent girls being taken abroad for circumcision, and to enable any such persons involved in the practice to be prosecuted under UK law when they returned. 'The Female Genital Mutilation Act 2003' repealed and re-enacted the 'Prohibition of Female Circumcision Act 1985'. The term 'circumcision' was superseded by the term 'genital mutilation' in the 2003 Act to reflect the severity of the practice.

In recognition of the high profile and universal condemnation of FGM globally, in January 1996 New Zealand incorporated an amendment to the New Zealand Crimes Act 1961, specifically pertaining to FGM, making the perpetuation of the practice illegal. The New Zealand Act also made it illegal to relocate an individual so the procedure could be performed.

The Section 204A Female Genital Mutilation, Subsection (1), the act begins by providing a number of definitions, including;

Female genital mutilation means the excision, infibulation, or mutilation of the whole or part of the labia majora, labia minor, or clitoris of any person.

Under Subsection (2), the amendment states; 
'...everyone is liable to imprisonment for a term not exceeding 7 years who performs, or causes to be performed, on any other person, any act involving female genital mutilation'.

Under subsection (3) it states;

Nothing in subsection (2) of this section applies in respect of -

(b) Any medical or surgical procedure that is performed on any person-

(i) While that person is in labour or immediately after that person gives birth; and

(ii) For the benefit of that person's health or the health of the child; and

(iii) By a medical practitioner or a ... midwife or a trainee health professional, or by any other person in any case where the case is urgent and no medical practitioner or ... midwife or trainee health professional is available.

This is subsequently qualified by subsection (4) that states;

In determining, for purposes of subsection (3) of this section, whether or not any medical or surgical procedure is performed for the benefit of that person's physical or mental health, no account shall be taken of the effect on that person of any belief on the part of that person or any other person that the procedure is necessary or desirable as, or as part of, a cultural, religious, or other custom or practice.

To further clarify the legal implications of any such procedure, subsection (6) of the amendment goes on to state;

It is no defence to a charge under this section that the person on whom the act involving female genital mutilation was performed consented to that act, or that the person charges believed that such consent had been given.

In summary, the 1996 amendment to NZ Crimes Act 1961 identifies that 'any act involving female genital mutilation' is illegal (Section 204A point 2 and 6 respectively) and further, that the act of FGM is illegal irrespective of whether or not it is undertaken with the consent of the person on whom the act was performed. Of particular importance for this study, is point (4) which states 'medical and surgical procedures may NOT be performed for reasons of; culture, religion, custom or practice'. This is not a direct reference to the act of deinfibulation but rather a restraint on possible sequelae to the act of deinfibulation. Point (4) ensures that re- 
infibulation after childbirth cannot legally be performed in New Zealand irrespective of culture, religion, or social custom or practice.

The focus of the legal implication is structured around medical or surgical procedures, but does include the mental health of an individual. This notion is worthy of further exploration, as medical and surgical procedures for reasons of culture, religion, custom and practice are prohibited yet are intrinsic, in many instances, to the mental health of an individual. This distinction warranted further investigation, in particular with regard to culturally determined ideals such as the ideal of 'beauty' and 'cleanliness', which some protagonists consider to be central to the practice of FGM and therefore critical to the comprehension of the act (Cameron \& RawlingsAnderson, 2001).

\section{Human Rights}

Because FGM is considered a deeply rooted cultural practice, defenders of the procedure, often invoke cultural relativism as a justification for its continued existence within their societies. This is the belief that the practice should not be judged from outside the cultural context within which it occurs.

According to Kanitsaki (1994) “Culture includes a particular people’s beliefs, value orientations and value systems, which give meaning, logic, worth and significance to their existence and experience in relation to both the universe and other human beings” (p.142). Culture determines both who you are and what you are, and critically is the determiner of gender roles and identity. Jones (2000) recognised that each culture has a distinctive moral code.

For Johnstone (2000), “culture exists logically prior to ethics, not the other way around"; that it is culture that produces the framework in which the ethical dimension occurs. One position that has been drawn from this concept is that of cultural relativism. Cultural relativism postulates that any practices grounded in cultural beliefs are not appropriate to be analysed by anyone outside of that culture. As it is the culture that determines the ethical framework any externally referenced analysis 
would leave the analyst open to the accusation of moral imperialism. As stated by Midgley (1991), this occurs where a culture believes 'that their way of moral knowing and thinking is not only superior but 'right', and is thus something to be applied universally to others whose moral systems they have judged to be inferior even 'savage'.' When confronted with the trauma of FGM Type III from a western cultural perspective, it is difficult to avoid the trap of moral imperialism.

Hughes (2006) contrasts whether FGM is a matter of custom and tradition or an abuse of human rights. The argument, brought forward by Hughes, is the World Health Organization's (1999) view that Female Genital Mutilation is a deeply rooted, traditional practice that has adverse physical and psychological consequences, in effect making FGM a form of violence against women. For Hughes therefore, FGM constitutes a breech of Article 5 of the Universal Declaration of Human Rights, which states that no one should be subjected to 'cruel, inhuman and degrading treatment'.

Hughes contrasts this perspective with that of the feminist writer, Germaine Greer, quoted by the House of Commons All Party Parliamentary Group on Population, Development and Reproductive Health (THS, 2002), when she compared FGM to cosmetic surgery carried out on American women and questioned our right to sit in judgement on other cultures.

Germaine Greer is not alone in raising this issue as Essen and Johnsdotter (2004) discuss similar ground. They highlight an apparent hypocrisy when "ScandinavianAfricans are tacitly ... pictured as potential mutilators...while genital alterations in non-African women seem to be widely accepted” (p.613). Further, they consider that this hypocrisy will remain as long as the legislature fails to make a distinction between adults and minors, or the motive behind the procedure.

Hughes' argument is different however as he suggests that Germaine Greer, although offering an interesting sophism, fails to recognise the significant degree of difference between cosmetic surgery; altering the appearance of the genitalia whilst still maintaining full sensitivity, and FGM, the excision of healthy tissue with long term physiological and psychological trauma. This has echoes of Essen and Johnsdotter's 
(2004) motive distinction, which places emphasis on the utilitarian aspect of the outcome of the surgery, and asks for whose benefit is it.

The topics canvassed within the debate over FGM are wide ranging and this breadth of topic has been carried over in to the literature search undertaken as part of the framing of this research within context.

\section{FGM and the Midwife}

A literature search was undertaken in order to establish the general context around the experience of midwives caring for women who had undergone FGM Type III. The review included online searches of several health and education related electronic databases. These included MIDIRS (Midwives Information and Resource Service), PUBMED and CINAHL (Cumulative Index to Nursing and Allied Health) and an electronic search of the Cochrane Library to identify any relevant Cochrane Reviews and manual searches of current research in refereed journals and legislative documents were also undertaken. Key words - Circumcision and Female Genital Mutilation were used.

To ensure that the literature was contemporary, the preliminary research was initially directed to sources published within the last ten years. However, on reviewing the citations it became apparent that the seminal literature around the topic of FGM extended beyond this period, and a number of older research pieces relevant to the topic were included. Although no discrimination with regard to country of origin was made, it was noted that the vast majority of relevant studies originated in England.

It was anticipated that the literature search would result in the identification of the general practice of midwives, with potentially a number of contentious issues arising. The actual findings of the literature search presented a different picture. In spite of the fact that a high percentage of the women who have undergone Female Genital Mutilation Type III require deinfibulation during childbirth, no literature pertaining solely to deinfibulation as a corollary of childbirth was discovered. Nor was there any 
research pertaining to the experience of midwives and the request to reinfibulate. The search revealed a significant body of information dealing with the nature and variety of FGM and literature pertaining to the procedure of deinfibulation Newman, (1996); Dahlen, Nanayakkara \& Bullivant, (1999); Rawlings-Anderson \& Cameron, (2000), but no articles that discussed the consequences of deinfibulation and how the midwife could deal with these directly.

The literature search highlighted that it is predominately African refugees who have the highest prevalence of Female Genital Mutilation Type III (WHO, 1996). These women originate from the horn of Africa in countries such as Somalia with $98 \%$ prevalence (WHO, 1996). Studies were written predominately by health professionals; doctor's, midwives, nurses, educators and social anthropologists (Essen \& Johnsdotter, 2004; Cameron \& Rawlings-Anderson, 2000, 2001; Parkin, 2001). There was a wealth of information on the physiological and psychological effects of the procedure, corrective procedures, and the legal and ethical implications around the procedure. However, there was a dearth of information on the midwife's experience encountering women who have had FGM (Type III) during the childbirth process. The literature search revealed only one article that broached the experience of midwives (Parkin, 2001).

Although Parkin's article includes 'a midwife's experience' as part of its title, the article only briefly recounts one midwife's first experience of providing care to an infibulated woman. According to Parkin during this encounter, the midwife experienced a profound sense of 'self awareness and shock', and uncertainty about the situation due to a lack of knowledge and experience of infibulation. Fortuitously a doctor, who had experience in caring for women with FGM, was available to manage the situation. The midwife expressed concern over the possibility of what might have occurred, and predicted "that this woman may have received inappropriate, insensitive care and what may have ensued” (2001, p. 421).

The experience cited in the article is used as a springboard to discuss the wider context and implications of FGM within the clinical setting. The focus of the article relates to how to improve the quality of care for the woman. While valuable from that perspective, the paper does not address the experience of the midwife beyond the 
initial exposure. Yet we are left with the impression that the initial exposure was traumatic for the midwife.

That this is the only article encountered in the literature search that considers the midwife's experience, highlights a gap in research within the context of caring for such women during the childbirth process. Although the natural focus in the literature has been on FGM, the implications and consequences for the midwife have been largely overlooked. This study intends to explore and describe this issue.

FGM based literature in the U.K.

Based on the results of the literature search, the U.K. was identified as the origin of the majority of English language published literature pertaining to FGM. The British Journal of Midwifery is one such journal that has published over ten articles pertaining to FGM in the last ten years. With many articles dedicated to this topic found within sole midwifery, nursing or obstetric publications, this represents only a small portion of such articles published within the UK.

The calibre of such publications is high. They include articles written by McCaffrey, Jankowska and Gordon (1995), a seminal piece of research on the management of female genital mutilation. This research highlighted the need for an African Well Woman's Clinic. Due to an increase in immigration from Somalia and Sudan into the UK at the time, a clinic was established in 1993 at Northwick Park Hospital, Harrow, England, that gave specialist care to infibulated women. The research provided a review of the women with FGM Type III attending the newly established African Well Woman Clinic, and identified the long-term complications of FGM, antenatal deinfibulation and recommended early gynaecological referral and surgery and educational programmes to increase professional awareness.

In 1997, Comfort Momoh established the African Well Woman’s Clinic at Guy’s and St. Thomas' Foundation Hospital Trust in London, providing a centre for excellence within a 'holistic' framework. It provided support, information and advice to girls and 
women who have undergone FGM. The clinic also provides FGM reversal, training, conferences and seminars for professionals worldwide (Lee, 2007).

Both these clinics document best practice from experience as specialist centres of excellence in caring for women with FGM. They provide a climate, which encourages the publication of research, and disseminate this knowledge to health professionals nationally and internationally. The presence of both dedicated clinics and a large population base to service appear to offer significant advantages in the availability and accessibility of relevant literature.

\section{FGM based literature in New Zealand}

By comparison to the U.K., even allowing for the population differential between the two countries, the literature search highlighted a paucity of New Zealand origin literature pertaining to FGM.

The New Zealand Ministry of Health produced the first piece of literature in December 1995 (MOH, 1995). This document gave a short summary of statistical data of FGM in relation to refugees settling in New Zealand from countries where FGM is practiced. It also discussed the health effects and needs of those affected by FGM and how FGM is positioned in relation to the law. The document reflected the 1994 and 1995 WHO publications on FGM. The 1994 WHO document highlighted an international shift away from thinking about FGM as primarily a health issue, and towards considering it as an issue of women's health and human rights. The 1995 WHO document was a technical working group report, which put forward clinical practice guidelines for health professionals.

In 1996 the NZ Crimes Act was amended to make the act of FGM, or the facilitation of the act illegal in New Zealand. In the same year, an article written by a third year student nurse from Somalia was published in 'Kai Tiaki', the New Zealand Nursing Journal. This article discussed the history, culture, varying degrees of FGM and the health complications as a consequence of the procedure (Ahmed, 1996). The 
following year, in response to the Ministry of Health publication, Denholm (1997) published an article, which gave a clear and detailed introduction to FGM within the context of New Zealand. This document drew on the guidelines contained in the World Health Organization (1997) document in management of pregnancy, childbirth and the postpartum period in the presence of female genital mutilation.

A national programme, co-ordinated by Nikki Denholm, was introduced in 1998 as a result of the influx of African Refugees entering New Zealand from 1996. The Refugees were predominantly from parts of Africa with the highest prevalence of FGM Type III. As a consequence the New Zealand Government, in line with the zeitgeist, mandated that an educational programme would be developed to address the perceived lack of information and appropriate treatment of women who were subjected to FGM Type III, and that this programme would be disseminated to the communities and health professionals.

Some four years later Smythe (2001) published an article that reflected upon the influence of tradition and politics on childbirth in different countries. Her exposure to FGM in Mali was discussed. However, since that date no other article pertaining to FGM has been published in New Zealand.

The lack of parity between the two countries published responses raises a number of questions in respect to the relative profile of FGM in the two countries, and the relative cultures related to published works within the two countries. At this point in time however, even allowing for the population differential, New Zealand origin literature pertaining to FGM is not well represented in published material.

\section{The Nature of the Midwifery Relationship}

The nature of the midwifery relationship within the New Zealand context is particularly pertinent, as autonomous independent practice encourages the development of a physically and emotionally intimate client/midwife relationship. According to Guilliland and Pairman (1994) midwifery in New Zealand is based on the philosophy of a women-centred partnership model of care. However, Leap (2000) 
challenges this description of the midwifery relationship, asserting that the relationship is not one of equality as a power imbalance exists between the midwife and the woman. Leap clarifies this statement by highlighting that women invite midwives to be with them to acquire their knowledge, skill and expertise, and that it is important that midwives recognise and own their capability.

As a result, the midwife, in a very direct sense, encounters the consequences of caring for a woman who has FGM Type III. The experience of this encounter is a 'key' factor, in the unravelling of the midwives' story. In exploring this notion further, the New Zealand College of Midwives Standards for Midwifery practice (2005); Standard One, states "the midwife works in partnership with the woman" (p.8). In order for the midwife to achieve this, she is required to facilitate communication, share all relevant information, identify her midwifery philosophy and share this information with the woman without imposing her value systems, whilst remaining culturally safe. In Standard Two “the midwife upholds each woman's right to free and informed choice and consent throughout the childbirth experience” (p.9). This raises the question, are midwives constantly striving for the best available evidence to challenge and change practice?

Midwives principally work with women in specific contexts, where both formal and informal relationships develop. Negotiating apprehension, satisfaction, emotions, complexities and challenges are part of what happens when women interact.

\section{Summary}

Although much has been written about FGM Type III and the ramifications for those on whom it is performed, little consideration has been given to those who must address the sequelae. Given the focus of existing research literature, this investigation into the experience of midwives caring for women, during the childbirth process that have undergone FGM Type III, will begin to shed light on the challenges experienced by midwives in that situation. Due to the nature of the physically and emotionally intimate client/midwife relationship that autonomous independent practice within New Zealand encourages, a qualitative methodological framework has been adopted 
to underpin this research undertaking. The next chapter discusses those methodological underpinnings. 


\section{Chapter Three: Research Design, Methods and Processes}

This chapter presents principles and concepts underpinning the research process. This process is informed by narrative inquiry as a qualitative methodology. As such, this interpretive paradigm expresses the emotional, chronological and contextual elements of the midwives' stories of their experiences of caring for women during childbirth who have undergone FGM. It goes on to discuss the processes and considerations undertaken during the recruitment of the research participants, to ensure that informed consent and confidentiality are addressed. It also outlines how the data were collected and analysed ensuring that rigour and trustworthiness were maintained.

\section{Qualitative Research}

This research is an interpretative study of the experience of midwives, caring for women during the childbirth process, who have undergone Female Genital Mutilation Type III. It focuses on the narratives of the midwives. The use of narrative inquiry resonates well with this research, as it is a qualitative methodology, which allows the story of the participants to be heard clearly. It minimises the hermeneutic interference implicit within the researcher's own professional experience, by using the participants own stories and reflecting these back to the participants to ensure that the meaning of the stories remain true throughout the distillation process.

Qualitative research practices developed in response to the growing unease with traditional views of what constituted research and the place of the researcher within it. While positivists sought to predict the world, interpretive theorists sought to understand it. Denzin and Lincoln (1994) defined qualitative research as that which uses a range of methods involving "an interpretive, naturalistic approach to its subject matter” (p.2). They also point out that the meanings people make of the phenomena they experience are a central focus of research that fits within the parameters of qualitative research.

\section{Narrative inquiry}

Narrative inquiry is one type of qualitative research. It has a focus on language, representation, legitimation, and the relationships between the researcher and the 
researched (Denzin and Lincoln 2005). Within this framework, 'narrative' is contextually embedded, emphasising the biographical and personal, revealing real experience, and looking for particular connections between particular events. Implicit within this statement is the notion that context is an important factor when making sense of, or interpreting, meanings people make of the phenomena they experienced. According to Markula et al (2001), epistemologically, context is centrally important in qualitative research, if we accept the premise that, as humans we create knowledge “through a subjective meaning-making process” (p.251).

Narrative is emerging more and more as a research methodology within midwifery research. My own narrative of my first exposure to this experience prompted many questions, which became the catalyst for this research. Any time that midwives come together, be it a study day, forum, reviews or workshops, stories from practice within practice are shared, (Chase, 2005). "Whilst continuing to value research and using it to inform our day to day work we should not underestimate how we question, learn and share an enormous amount of knowledge by listening to each other and the women we attend (Leap, 1998, p.3”).

Clandinin and Connelly (2000) take this further by stating that novices can reflect on the stories being told and through this process develop their professional practice. Narrative is part of a midwives practice, or according to (Hardy, 1968 in Conle, 2000) a basic mode of thought. Consider the number of times a midwifery colleague responds, "that reminds me of ... and the narrative segment of a lived experience follows” (Conle, 2000, p.53). Clandinin and Connelly (2000) explain how, "[midwives] generally tell others of their experiences in the form of stories because ...stories are the closest we can come to experience...” These stories emerge from personal and social histories where people live stories, and in the telling of them reaffirm them, modify them and create new ones”(p. 415). Sharing stories are fundamental to the culture of midwifery (Flint, 1986; James, 1995; Leap, 1998).

Narrative inquiry was adopted within this research in order to explore, gain insight and understand the lived experience of each individual midwife. Narrative inquiry is particularly suited to this endeavour as it is a distinct form of discourse, which validates the inclusion of the emotional states and personal interpretations of the 
narrator's experience of particular events. According to Hinchaman and Hinchman (2001) narrative is a way of understanding one's own and others' actions, of organizing events and objects into a meaningful whole, and of connecting and seeing the consequences of actions and events over time. Unlike a chronology, which also reports events over time, a narrative communicates the narrator's point of view, including why the narrative is worth telling in the first place. Thus, in addition to describing what happened, narratives also express emotions, thoughts, and interpretations. Narrative, unlike scientific discourse, highlights the uniqueness of each human action and event rather than their common properties (Bruner, 1986; Polkinghorne, 1995).

Clandinin and Connelly (2000) observed that, "narrative inquiries are always strongly autobiographical" (p.121), defining narrative inquiry as "both phenomenon and method" (p.416). They proposed that narrative relates both to the "structured quality of experience [and to] patterns of inquiry’ (p.416). Goodfellow (1998) introduced a useful distinction, distinguishing between the terms 'narrator' and 'narrativist'. For her, a narrator tells stories, while a narrativist is a constructor or interpreter of stories. This clarifies the relationship of the role of participant, as narrator, and the researcher as narrativist.

Issues related to authenticity in using narrative as a framework for this inquiry and analysis have to be considered if an accurate representation of the experience is to be realized. At the same time, ethical issues relating to sensitivity and vulnerability needed to be accommodated. As stated by Brunner (1999), this can be achieved by distilling the essence of experiences, by combining them into a collective narrative, using literary devices to evoke experiences. Brunner's observation highlights what was sought in the co-operation with participants when she said that:

When we ask questions of ourselves or others, we wish to hear the true song. When we repeat what we have heard from others, we hope to repeat the true song (p.177).

In the case of this research, the true song is not just the verbatim accounts contained in the interviews; it is about the creation of a sense of truthfulness and evocation of 
actual experiences that may talk to and resonate with the lives of others who may read the story.

According to Koch (1996) it is the responsibility of the writer to "show the way in which a study attempts to address the issue of rigour [and] it is for the reader to decide if the study is believable” (p.178). The reader should be able to 'audit the events, influences and actions of the researcher' (p.178). As this study is informed by a narrative approach, it captures the midwives stories of the phenomenon in question. It is about finding the best words put together in the best way to capture the stories in their full richness and depth.

\section{Methods and Processes}

This section describes the key methods of the research, such as the selection criteria for research participants, the interview process and the analytic strategies used in analysis of the data. It also highlights some of the ethical considerations and research trustworthiness foreshadowed in the research approach as data was reviewed.

\section{Study location}

The research was undertaken in the Waikato region. The two main factors which contributed to the decision to select the Waikato region are that the region contains a high number of midwives per capita within New Zealand and within the past ten years, immigration trends within the region have included populations from cultures that are known to have engaged in the practice of FGM. According to census data 283 Somalia, Congolese and Djibouti females, aged 15-24 years reside within the Waikato region (Fraser, 2005).

\section{Selection criteria and participant numbers}

As the research topic was experientially based, the critical selection criteria focused on those midwives who had experienced the phenomenon; that is, midwives who cared for women who have undergone Female Genital Mutilation Type III. As the study focussed on the New Zealand experience, within it's particular legal 
framework, only those midwives registered to practice within New Zealand and who experienced the phenomenon within New Zealand were recruited.

Due to the qualitative nature of the study, the proposed data collection process was intensive and sought descriptive/ narrative depth rather than quantity. Sample size in qualitative research, according to Sandelowki (1995), is a matter of judgement and experience in the following: evaluating the quality of the information collected against the uses of which it will be put; use of the particular research method; and purposeful sampling strategy employed. She says that an adequate sample size in qualitative research is one "that permits, by virtue of not being too large, the deep, case-orientated analysis that is a hallmark of all qualitative inquiry. That also results in, by virtue of not being too small, a new and richly textured understanding of experience” (p.183).

A maximum of six participants, were sought for the research, in order to ensure that adequate time could be given to deep, storytelling analysis. The number of participants for the study was determined by the time frame of the study and the emphasis on fine analysis of the data. The research was to gather the experiential and contextual commonalities of the narrators. Within the size and scope of this study, larger participant groups would result in a coarse analysis and undermine the benefits of narrative inquiry. A larger group would result in the allocation of a shorter time for the interview with the participants, truncating their response time and reducing the opportunity for them to express the range of their experiences. This would result in producing a broader but shallower data pool, providing a greater breadth of experience but reducing the depth to which these experiences were explored.

\section{Recruitment process}

To initially raise a broad awareness of the intended research, flyers were prepared outlining the research topic (Appendix A). These flyers requesting midwives to take part in the research study, were posted out to individual midwifery group practices, and placed on the hospital notice boards within the Women's Health division of the Waikato Hospital; Antenatal Clinic, Delivery Suite, Antenatal and Postnatal wards and within the two primary birthing units in Hamilton. A two-week time period was 
given for consideration, with a response date on the invitation. Those midwives interested in participating in the study, or who required any further information, could contact either my supervisor or me.

Those midwives, who agreed to be research participants, received an information sheet outlining the research aims, the research process, (including recording of interviews), interpretation, ethical procedures and confidentiality (Appendix A).

\section{Research participants}

While the number of participants in this research may be deemed small, I am mindful of Goethe's idea that "the Particular is always more than a match for the universal; [and] the universal always has to accommodate itself to the Particular" (Weber, 2007). This suggests that in order to understand the world at large, we need to do a better job of understanding the world as it is lived by individuals, for it is they who help make the [midwifery] world what it is.

Six independent midwives responded to the initial invitation, and agreed to become participants. Two subsequently declined citing lack of time to commit to a research study.

The four remaining participants were experienced independent midwives, with experience ranging from ten years to over twenty years registration. Three participants had completed their midwifery training overseas, after working as registered nurses. Although they had a collegial relationship as independent midwives, they did not work in a group practice together. The participants had variety in their breath of experience. The participants had worked in a variety of practice settings over the years, including hospital, caseloading and geographical locations. They were all enthusiastic to share their experiences, and cognizant that by revealing their stories, they would contribute to 'broadening the horizons' of midwifery knowledge in this field. 


\section{Data Collection}

This section considers some of the issues inherent in the analysis of this data.

\section{The interviews}

The research data were generated from unstructured in depth interviews with the participants. The interviews were conducted at a mutually agreed time, date and in a private location. One participant chose to have the interview conducted in her own clinic, and the other three, in a reserved room used by midwives within a primary birthing unit. Although the participants themselves determined the length of each interview, a provisional one-hour timeframe had been planned. Several authors suggest that ninety minutes is the optimum length for a qualitative research interview (Hermanowicz, 2002; Seidman, 1998). I therefore suggested to interviewees that the interview may be approximately sixty minutes long, but might go on for as long as an hour and a half. I believe that this was helpful as it gave them a timeframe to work to. Two of the interviews ended up being an hour and a half, simply because they had so much to say about their experiences.

Informed consent was sought on the day, by way of signing a consent form prior to undertaking the interview (Appendix B). Each participant was encouraged to ask any questions they had about the study and reminded that they could withdraw their consent at any time during the research process. The interviews were undertaken using open conversation, with flexibility in the timeframe when the individual participants ‘story-telling' continued.

Four primary trigger questions were developed to elicit a response from the participants'.

1. Before you cared for a woman who had been infibulated, had you read or heard about 'Female Genital Mutilation'? If so, what were your initial thoughts and feelings'?

2. Tell me about your initial thoughts and reactions when you first saw a Type III infibulation?

3. Tell me about your experience of caring for a woman, during the childbirth process that had undergone 'Female Genital Mutilation Type III’? 
4. Have you encountered any ethical dilemmas, challenges or conflict when caring for women who had been infibulated?

According to Chase (1995) the researcher can prepare for narrative interviews by developing a broad question that will invite the other to tell [her] story. There was no prescriptive interview schedule, as an interpretive “openness” was essential. The questions that were formulated initially, to use as 'triggers' during the interviews, appeared to be effortlessly incorporated into the stories of the midwives and were not needed in the end.

All interviews were audio taped with the participant's permission. Taping occurred as unobtrusively as possible. However, for the sake of audio recording quality, the participants were required to sit in closer proximity than would be in a 'real' conversation context. Other than the participant, no one else was present in the room.

The purpose of the interviews was only to hear the stories, and to assist the participants in teasing out the meaning in their stories. No agreement or disagreement was expressed during the course of the interview by the interviewer. Nor did the midwives look for approval or reassurance when telling their stories.

While Oakley (1981) identifies some problems with interviewing in terms of power relations between participants and researchers, it is nevertheless a common research tool, used for a variety of purposes. The issue that Oakley highlights is that the researcher is advantaged in that they have control over what questions are asked. However, by providing participants with the trigger questions prior to the interview they were able to better prepare for the interview. Three participants had requested in advance to be provided with a set of the 'trigger questions'. This goes some way in addressing the power imbalance identified by Oakley.

An interesting feature of each interview was how little prompting the midwives needed; the midwives were more than willing to share their experiences in telling their story. The format and scope of the interview enabled participants to find a starting place for themselves, and they took advantage of this, which helped put them 
at ease. Graham (1984), Mishler (1986), and Riessman (1990) support this notion by emphasising that the interviewer simply empowers respondents to talk freely.

The interviews were transcribed verbatim, by confidential secretarial services, who signed a confidentiality contract (Appendix C). In order to maintain confidentiality, references to named third parties and institutions within the interview were removed during the transcription process.

Upon return of the initial draft of the transcripts, they were reviewed against the recorded interviews and a number of grammatical errors, medical and midwifery terms were corrected. The corrected transcripts were then returned to each participant, with an information letter giving an explanation as to the transcription process and a return of transcript form, asking participants for their release of the transcript for use (Appendix D \& E). This initial review of the transcripts began the process of familiarization with the transcripts.

The participant was free to delete any parts of their transcript that they did not wish to be included in the study. As noted by Swanson-Kauffman and Schonwald (1988) the marks of a good qualitative interview, are best judged by the person being interviewed, who knows when they have offered in-depth dialogue. In all instances, the research participants felt that the transcripts reflected the interview and no changes or deletions were undertaken. However, some participants had concerns about the sensitivity of some of the comments they had made and what appeared to be 'poor' language. Reassurance was given once again with regard to confidentiality and that the focus of the study was not on spoken language but rather the content of their stories. These transcripts formed the basis for comparison, analysis and interpretation from which the commonalities of the experience were uncovered.

\section{Data analysis}

The analysis of the data was an iterative process. Listening to the taped interview and rendering a version of that in writing was a process that involved a discursive approach and interpretation. Repeated listening helped develop the rhythm of the conversation and on each hearing, extra dimensions were added. 
The second hearing was undertaken, by listening to the entire 'story' without pausing and the next three listenings concentrated mainly on the words and phrases that suggested particular emotional engagement with the experience, for example; 'I felt', 'I believed' and 'this made me want'. Further listenings focused on the pauses (voiced and unvoiced) between the words, the stresses and the tone shifts, the laughs, the sighs and the intakes of breath. A large proportion of the meaning of language lies in the nuances in the context of the spoken word. A pause, gap or shift in tone, can often change the meaning of the word, depending on the context in which it is heard. As a result, subsequent listening revealed additional meanings from that of the transcript alone. In all, over thirty hours of time was spent listening to the interviews and annotating each of the transcripts.

Due to the open nature of the interview process, the stories were often punctuated by lengthy expressions of experiences with varying degrees of relevance to the topic in hand. This often made it difficult to identify particular responses and a logical order.

In order to give some form to the discursive structure of the interviews, a matrix was developed which listed the four trigger questions and the range of responses within the context of the interviews. Different coloured highlighter pens were used to mark recurrent phrases and 'parts of stories' which were then analysed as common across stories and grouped together, into what became key themes. For example, "It was not in midwifery curriculum”. "I didn't understand”. “... all quite scary and obscure, where was it going to go"? "... such a tiny opening, how is this baby ever going to get out"? "How was this baby going to come out”? "I felt that I'm kind of stitching her back up again". "Did not want to cut upwards". "Woman wanting to be cut upwards and resutured”.

According to Butcher (1998) immersion by the researcher into each individual story, identifies key phrases, themes and words. This process required constant reiteration, with the responses being refined and checked against the original transcripts to maintain the intent and focus on individual experience as interpreted from the interview. The themes began to blend and from this process the true song began to sound more clearly. 


\section{Ethical considerations}

Ethical considerations were identified and addressed as part of this research study. These included establishing a recruitment process, with midwives giving informed consent to be a participant, with the opportunity to withdraw at any time, and the application of the principle of participation. The principle of participation, when applied to social science research, ensures the inclusion of participants is not discriminatory to ethnicity or years of professional experience. As a consequence no attempt to employ a probability sample was made which allowed for a good participant mix, rather than recruiting solely midwives working in a specific field. The midwife did have to have experience, caring for women during the childbirth process, who have undergone FGM.

Consideration was given to sensitive issues, which may be distressing to the research participant. It was made clear to the participant that she could terminate the interview at any stage should she feel uncomfortable with the direction of the interview. Also contacts for counselling support were offered at the end of each interview. In addition participants were encouraged to have a support person accompany them, if they so desired, who they could talk with to debrief after the interview. No participants chose to bring a support person.

To ensure the confidentiality of the participants throughout the research study, being mindful of protecting the rights of any individuals, all participants' identities would be protected and any names used in the study have been changed.

According to Polit and Hungler (1997) the participation of human subjects in research, especially if one is researching experience, must take care to ensure the welfare of participants is protected. To protect participants' rights, permission was sought to tape record interviews. All the participant midwives were made aware of the intention to publish the findings and had the opportunity to review transcripts, signing a release of transcript document, prior to any elements being published. All recordings and transcripts of interviews are kept in a locked cabinet and will be destroyed five years after the conclusion of the study. 
Ethical approval for this study was granted from, Victoria University of Wellington Human Ethics Committee in January 2007 (Appendix F).

\section{Research trustworthiness}

This study used a model of research that attempts to understand participants' experiences, in their own terms, in relation to the research question. In qualitative research terms, 'narrative' often focuses on the biographical and personal, revealing real experiences. The intention is to reveal stories that speak for themselves as being true to the data and that are vital. Working within the methodology such stories are 'pure', as their reflection of the data makes trustworthiness transparent.

Trustworthiness within research, or 'rigour' as it also referred to in some references, enables others to scrutinize the inquiry for methodological worthiness (Roberts \& Taylor, 1998). To ensure trustworthiness occurs within any research study, meticulous steps and a clear and consistent methodological process are required to be followed. Lincoln and Guba (1985), qualitative researchers, proposed three fundamental criteria to ensure trustworthiness: credibility, transferability and dependability.

Within a narrative methodological context, credibility is achieved through showing how interpretations are arrived at during the inquiry. As this is a narrative study, it sought to capture the personal experience by midwives of the phenomenon in question. It is about finding the best words put together in the best way to capture the experience in its full richness and depth. This was achieved by the use of verbatim quotes from the transcribed interviews, presenting the 'voice' of the participants to make the experience come alive (Mitchell and Charmaz, 1996). As a result, when midwives were given the opportunity to give feedback on their transcripts, they could recognise their own descriptions, giving credibility (Sandelowski, 1986).

Transferability allows the findings of the research to be applied to other contexts. For Koch (1998) this ability is reliant upon the degree of parallel between the two contexts. Denzin and Lincoln (1994) suggest that qualitative research uses a range of methods implicating context as an important factor. Within this study, a 
conscientious effort was made to record the nature and environment in which the phenomenon was experienced. According to Davidson and Tolich (2003), the research question should clearly reflect the concept the researcher is actually looking for and the extent to which the study results can be applied to a wider population.

Dependability relies on making explicit 'decisions taken about the theoretical methodological and analytic choices throughout the study’ (Koch, 1998). For Koch the reader should be able to "audit the events, influences and actions of the researcher" (1996, p.178). Byrne (2001) refers to the audit trail as record of the research process for external validation in assessing the rigour of the study. Lincoln and Guba (1985) also discuss the use of audit to address dependability.

Reflexivity is another important component considered throughout this research. Guba and Lincoln (2005) consider reflexivity as the process of reflecting critically on the self as researcher. This has been achieved by adopting a reflexive stance in selfawareness, and positioning myself within the study with the focus on the participant and their story (Corbin and Morse, 2003). Part of this process has been to keep a reflective journal and by following the research process of data collection and analysis by sign posting to readers ‘what is going on’ (Koch \& Harrington, 1998).

Having being exposed to the phenomenon myself, and with the midwives telling their stories, thoughts and feelings began to be awakened within me as I could relate to their stories. The reflexive stance ensured my own biography did not interfere with my desire to truthfully represent others’ stories.

\section{Limitations of the study}

The limitations of this research relate to the ability to generalise the findings of the study. As with most qualitative methodologies, the distillation of the experiences produces a greater understanding of the phenomenon that is generally recognisable. It does not in itself allow direct transference of the details of the study to similar situations, as the outcomes are as much researcher dependent as participant dependent (Tobin \& Begley, 2004). Also, as powerful and applicable this research is in the 
context of the time and place in which it is written, someone else would have to accordingly make it their own.

The recruitment of the participants was a slow process, with midwives reading the invitation to participate, and initially being encouraging and enthusiastic about the research topic, only to decline to take part, citing time out to undertake an interview would be time consuming. Six midwives were initially recruited for the study, however, two later declined prior to the interview process. Within the context of qualitative research and narrative inquiry as a research methodology, the remaining four were considered an appropriate number of participants; due to the rich and textural data generated by the interview process, and the available time to analyse the data within the scope of this study.

All of the midwives were from independent practice, although no attempt to employ a probability sample, they did meet the criteria for participation. Although a mix of midwives from a variety of practice settings would have possibly given 'something' different. That will never be known within this research.

Creating a single story of experience proved difficult, given the depth and intensity of the experience of this phenomenon in the midwives' professional lives. To this end, creating the story with a third person protagonist kept faith, trust and sensitivity to the data. Although it may be considered that developing such a story as a findings chapter cannot fail to result in a work of fiction, the intent of the story is to distil the essence of the specific experiences and hence be recognisable by the participant as being their story. It was not the intention that the true song be seen as a generalization of findings.

\section{Summary}

The research design, methods and processes have been presented and discussed within this chapter. In the opening of the chapter, narrative inquiry as a research methodology is discussed with regards its suitability to answer the research question of midwives telling their story. The recruitment process through voluntary participation and analysis of the data has been discussed. Finally the limitations of the 
study were highlighted. This leads the research into the next chapter of discussion of findings. The discussion contains verbatim quotes from the midwives' stories and the analysis of the themes, which have emerged from a study of the narratives. 


\section{Chapter Four: The Findings}

The analysis of the data enabled the development of a narrative, which encapsulates the experience of the midwife through her journey from a naïve awareness of an academic condition to an experienced and impassioned participant in the care and condition of women with FGM. For the midwife this journey involved a very personal cross-cultural confrontation that prompted a search for knowledge, support and answers that had ethical, medical, legal and educational ramifications. Although it is expressed as being the experience of an individual midwife, the following metanarrative is the distillation of the experiences of the midwives who participated in the study. Bruner, (1993) supports this by discussing how possible it is to work with research participants in a variety of ways including fictionalising narratives, using narrators as characters or even using multiple characters who may "speak in many voices” (p.413). This chapter then goes on to identify and explore four main themes that emerged out of the midwives story, known as the true song.

\section{Data Analysis - The True Song}

The following story is the meta-narrative distilled from the stories told by the participants of the study. It is not a generalisation of the stories, as it does not focus on only what is common between them and thereby produce a reduction of the original stories. Rather this meta- narrative has sought to capture the particulars of each individual's story and blend them in a manner that remains authentic to the original stories in the hope that each participant would say 'this is my story'. As all the participants in the research are midwives, and out of respect for the profession, the noun midwife, has been italicised and should be read as a personal pronoun.

Prior to caring for a woman who had been infibulated, the midwife had little information about FGM Type III. She also had no recall of ever having the information discussed within her midwifery curriculum when training. The information she had, she had gleaned from overseas nursing and midwifery journals, or recalled from attending a national workshop years previously. Although the midwife recognised she only had limited knowledge of the topic, she found it difficult to obtain further information. She found that those few midwifery colleagues, who had had clinical experience, seemed disinclined to share it freely. 
The anxiety this obstacle presented was only compounded by the increased likelihood of having to come face to face with this condition as the migration to New Zealand of women who had undergone this procedure in their homeland (African Refugees) increased in the mid 1990s. The introduction to such disfiguring trauma, combined with the lack of accessible information on how to treat the condition, created a climate of stress exacerbated by ignorance. For the midwife, caring for a woman with FGM Type III was inevitable, and with no other viable source of knowledge available, she attempted a period of self-education on the practice and procedures involved in caring for women with Type III FGM, drawing on what few resources she had available.

With some increased knowledge came a greater empathy and compassion for the women who had undergone FGM III, and increased apprehension of the midwife over her knowledge base. In spite of the knowledge gained, unanswered cross-cultural questions remained about what was culturally appropriate. The midwife was plagued with doubts and uncertainties about the altered anatomy and how she was to approach the woman in a way that was culturally safe for both parties.

In spite of these concerns she strove to maintain normal clinical detachment during the antenatal period with the knowledge of 'altered' anatomy; she found herself anxious over the dilemma as to when it was appropriate to view the woman's vagina. It was not something that was done without good reason, and was the knowledge that this client had been subject to FGM Type III sufficient reason? Or would this act in itself violate the woman's trust and simply expose the inexperience and insecurity of the midwife, making matters worse for the woman in the process?

The midwife's education and previous training had done little to prepare her for the reality of seeing for the first time a woman who had Female Genital Mutilation Type III. The initial reaction was one of shock, disbelief and confusion; the familiar had been replaced by the unrecognisable; only to be followed by more pragmatic concerns over the functionality of the modified anatomy; how was the baby going to get out of such a tiny opening? For the midwife, faith in the human body and the natural process of childbirth was challenged by the traumatic mutilation of FGM Type III. The ability of the woman to birth without deinfibulation had been lost, necessitating intervention, which is the antithesis of midwifery practice. 
The necessity of deinfibulation introduced further challenges and uncertainties for the midwife. The act of deinfibulation itself, although necessary and beneficial, seemed to re-awaken the trauma associated with the original mutilation of the woman. It was not uncommon for the emotional scarring from the original experience of FGM to resurface anew with the women. This was indicated either through them appearing disassociated during childbirth, or exhibiting excessive fear with infiltration prior to an episiotomy due to the initial vaginal intervention. In addition the midwife often felt pressured by the woman's female support people; often the matriarch of the family who expressed expectations of how the deinfibulation should be performed, contrary to best practice, and would subsequently pressure for reinfibulation of the woman.

Initially, while inexperienced in caring for such women, this pressure was exacerbated by the midwife's insecurity over her knowledge base. Even when seeking confirmation from her colleagues, or by observing other health professionals, the midwife encountered considerable deviation from recommended practice.

With experience, many of the midwife's anxieties and insecurities dissolved, while some were replaced by more real concerns. The care of primigravida women who had undergone FGM still provoked anxiety, as the ability of the perineum to stretch to allow safe facilitation of the birth remained in doubt. By contrast, the multigravida woman presented minimal concerns as she had previously birthed. The ability of the perineum had been proven to stretch sufficiently to allow the safe facilitation of the birth.

In spite of the greater experience of caring for women with FGM Type III, the midwife remained concerned over the potential risks involved in caring for women who had been infibulated. Although not consciously concerned over a specific risk she preferred the relative safety of a secondary care facility to facilitate the birthing experience, with the knowledge that this environment offered greater support should things not proceed safely.

But even within this environment the midwife recognised that things were not ideal, both in terms of the support and knowledge base offered by other professionals and the clash of cultures. Even within the environment of the secondary care facility it 
was not uncommon to encounter a lack of understanding and support from other health professionals. Acting as the woman's advocate, it was often difficult for the midwife to reconcile the cultural differences whereby the only male that was to supposed to touch the woman was the woman's husband, yet often only male doctors were on call when further medical consultation was required.

After having repeatedly surmounted all of the obstacles of facilitating the birth process for a woman who has FGM Type III a number of concerns remain for the midwife; having strenuously acted to ensure the woman had choice about what was to happen to her and her baby. The requirement to leave her deinfibulated; often in contradiction to the woman's own wishes, appeared to go against the ethos of choice. And even knowing the legal stance of FGM the midwife is uncertain where to go should she encounter a situation where she believes that the requirement to leave the woman deinfibulated should be challenged.

For the midwife there remains the personal burden of dealing with the trauma of confronting FGM Type III, the lack of support for herself in sharing or being counselled over her experience and the knowledge that although associated with much hand wringing when first encountered, the spotlight has shifted from the subject some years since and she must continue on.

\section{The Themes}

\section{Introduction of the themes}

This true song contains within it the themes that reflect the midwife's experience of caring for women during childbirth with FGM Type III. These themes were derived from the interviews undertaken with the participants and were used as guides to fashion the form of the true song. These themes; feeling unprepared, negotiating the cultural gap, the traumatic reality of deinfibulation and tensions and paradoxes are intrinsic to the true song as it is a distillation of the experiences expressed within the interviews. It is through the distillation of the experience that a deeper understanding can be revealed about what it means to care for women during the childbirth process, who have undergone Female Genital Mutilation Type III. The identification of these 
themes was fundamental to the creation of the true song and was as a direct consequence of the data analysis.

During data analysis, repeated listening to the raw data began to reveal general topics that arose in the stories that had been told. With repeated listening these general topics began to coalesce into distinct themes within the interviews. These themes, although manifesting themselves at different times within the course of each individual interview, were often expressed with almost identical phrases by the midwives who told their stories. That these themes are also present within the true song verifies and authenticates the true song as an accurate reflection of the original experiences. The four main themes make transparent the midwife's journey through the experience of caring for women with FGM Type III.

\section{Feeling unprepared}

The first of these themes, feeling unprepared, reflects the paucity of relevant information and education available to the midwives as a prelude to their first exposure in caring for women who had FGM Type III. All of the midwives who participated articulated that initially when caring for women who had FGM Type III, they had a limited knowledge base.

...it was not in my midwifery curriculum. I had thought about it, as a young midwife and was wondering when I came across [it] how I would actually deal with it. I kind of experienced it in myself as a fear ... because it was something I didn't understand culturally and I didn't understand physically. I used to think things like how can these women get pregnant. Or if she is urinating, is she more likely to have infections when she's pregnant because of the difference that she's got there and is it less hygienic and so more susceptible to infection. I also used to think about when I'd met a woman who had Type III, what was I going to do for her in labour.

This limited knowledge base made it difficult to anticipate what to expect and how to undertake any relevant procedures. This was clearly expressed by one midwife who stated that although she had attended a presentation

... the stories, [that were] being told and how these women had undergone the procedure, it was all hard to hear and hard to listen to. [It was hard] to 
work out that we as people, are doing this to others and, people [still want] to do it. I just couldn't kind of grasp that. There was not much, at that time about it in New Zealand. It doesn't happen here does it? But I had heard about it obviously from England before I came here. But I hadn't come across anybody that's had the procedure 'til after; I'm sure...that presentation.

Another midwife had never had it presented in her midwifery training in England; nor read anything in midwifery journals or explored it further and made this comment.

I kind of had a general idea...but didn't really know what it would look like or what it really entailed or ...how I was going to deal with it. I knew that I had to know with the first client coming through, then I did do some reading and [tried] to find about what to expect. That was all quite scary. I didn't know if it was going to be like this or like that and what I was going to do. And because it was quite new to New Zealand, people didn't have the answers... when I asked the doctors at the hospital they really didn't know until it actually happened.

The midwife did not elaborate further on what information she accessed and how.

\section{Negotiating the cultural gap}

The second of these themes, negotiating the cultural gap, evolves from this lack of knowledge, but highlights the confusion and trepidation that the midwife experienced as a consequence of attempting to partner the women across a cultural divide. For the midwife, the notion of partnering a woman through her pregnancy became fraught with difficulty, when even the most fundamental assumed common experiences are absent. Lack of common ground and expectations gave rise to uncertainties and concerns over appropriate protocols in and around FGM Type III. The knowledge of a cultural difference without an adequate grounding in that culture resulted in an immediately intractable dilemma as one midwife articulated.

I visualized her vagina for the first time in [labour] how was I going to approach her culture in a way that was safe for her, but also safe for me ? I found it quite a challenge to talk to them, her husband and herself about it but I found quite quickly that they were very open about what I needed to do to make it okay. 
This dilemma manifested itself by reducing the midwife to inaction. None of the midwives in the study had observed their clients' external genitalia to inspect the extent of mutilation, antenatally or prior to labour. One midwife commented,

because I didn't want her to feel that she was... different... because actually that's her norm...and why would I want her to feel that I was insecure...even though I really was.

The inaction on the part of the midwife ostensibly arises from a concern for the woman in her care, in the first instance, and respect for her culture. Implicit within that sensitivity to cultural difference however is a degree of self-doubt by the midwife over the appropriateness of such an action. The midwife was concerned, that the act of inspecting the genitalia might in itself reveal a lack of confidence in their ability to competently handle the situation.

This difficulty is further compounded when the ability to converse directly with the woman is lost due to language differences. The barrier of cultural differences compounded by the chasm of a different language relegates the role of advocate for the woman by the midwife, to one of second-guessing within a vacuum. Often the only alternative available is to utilise an interpreter. However, to further compound the issue, often the only interpreter available is the woman's husband. When practicing within the cultural framework of a patriarchal society it becomes extremely challenging to be a woman's advocate when the conduit for communication may have a vested interest in an alternate agenda. As stated by one of the participants,

the language difficulty [is] often [the] husband is interpreter. She doesn't speak to me directly, it's always through him and I find it very difficult sometimes, because I would really like to get to know who she is, but I can't on, a woman to woman level, because he is in the way. He's always insisted from the word go that we don't need a female interpreter ...

\section{The traumatic reality of deinfibulation}

The third theme, the traumatic reality of deinfibulation, reflects on the effects on the midwife of encountering the physical reality of FGM Type III, the range of emotions that are evoked and the difficulty in maintaining professional decorum while being 
confronted by such trauma. It also highlights some of the ramifications, expected or otherwise encountered by the midwife while caring for women with FGM Type III.

For the midwife, the initial exposure can be quite traumatic and have lasting ramifications. One participant recalled her reaction and with candid self-analysis stated,

I was quite horrified and it must have really got to me because it's still there.

FGM Type III mutilates the genitalia to such an extent that the midwives felt that they no longer had a point of reference. Another midwife commented,

I just couldn't work out what I was seeing, and how I could relate what I was seeing to what I knew of female anatomy. I just couldn't kind of picture the anatomy from diagrams, but they didn't equate. I couldn't put the two together.

Having reconciled themselves to dealing with the reality of the situation that confronted them, the incomprehensibility of what was meant to occur with the remnant external genitalia left the midwives incredulous. As one midwife expressed

... I just thought I don't know if this is physically possible.

Or as succinctly put by another

How was the baby going to come out of this small orifice?

A successful outcome required the intervention on the part of the midwife that inevitably led to either deinfibulation or an episiotomy. For midwives, the nature of the intervention itself is of concern. One midwife commented,

I was worried about when the baby came, at what stage was I to deinfibulate, and could I do it because I don't even do episiotomies in my practice unless it is a very serious matter. So, I found that quite a challenge as well, and when it came down to it, I didn't reinfibulate her.

For another midwife the concern over the intervention was compounded by her inexperience and the lack of collegial support. 
I can remember the mechanics of it but they were telling me, somebody mentioned that she needed an episiotomy and you know it looked like she needed something... but I couldn't figure out and I remember the lecture, yes it should go up but that felt so foreign to me.... it felt kind of strange and how do I do it and there was nobody there to support me...what do I do and how do I do this...the registrar was not very helpful...possibly the registrar didn't know but got out of there fast, but the ladies support people were saying cut her down... and in the end I gave in...I did an episiotomy this then needed stitching and I felt so gross and felt sick to my stomach because I felt I had circumcised this woman once again...and I didn't feel bad doing the episiotomy because it was needed...but when I came to stitch up, and I felt that I'm kind of stitching her back up again... I felt, oh my goodness what have I done.

Ever present within this scenario is the building urgency around the birth, further compounded by the voice of the woman, finding herself in a stressful and foreign situation, deferring to her societal expectation. At times, irrespective of antenatal instruction and preparation of the woman by the midwife, the midwife found herself being subjected to specific direction.

Once a woman, this particular old woman was wanting me to cut here, cut there and cut up and cut down. You know, to do a bilateral. Posterior episiotomies and up, and I was going no, no, no we just, we wait, we wait... and she was going up, up cut, cut you know she didn't have any English, but I knew by her hand actions that she was going like this, and I had to say to one of the other women who was there, like "could you please tell her to keep her hands away".

The need for decisive action and the sense of urgency was clearly conveyed in the following quote from one of the participants.

Where was it going to go [because] there was such a tiny opening and yet the woman's body was bulging ... and this baby was demanding to be born... and yeah I found that quite disturbing because it [was] like...the natural forces of birth are being held up. But of course it did come out ... with the aid of a rather large episiotomy.

For the midwife, the greatest challenge may come with the aftermath of the delivery. The consequence of performing deinfibulation or an episiotomy to support the safe facilitation of childbirth usually requires some reinstatement of the perineum. Often the reinstatement is not consistent with the expectations of the women, 
I requested them [hospital doctors] to [deinfibulate]...and they did...to a certain point. But not the same as what it was.

However, disturbingly, the act of reinstatement appears to reawaken the trauma associated with the initial act of mutilation and infibulation. As heart wrenchingly recalled by one midwife preparing to repair a perineal tear on a woman after a delivery.

I tried to get through to her that she needed to have some stitches. When she saw the needle with the suture,... she was begging me not to do it, so I said fine, I won't stitch you, I'll leave it...and you know she was almost, saying oh thank you, thank you. [I was] so grateful that I wasn't suturing, and that made me realise what bad experience [and] how traumatic it had been for her [and] how she thought that it was going to be a similar thing, that I was going to put stitches in and it was going to be sore. She [had] tears come down her face.

Although typically the women try to appear stoic toward the reinstatement, as one midwife commented,

...they're emotionally wrecked and physically scarred by it.

The experience for the midwife becomes one where she must not only guide the woman through the emotional roller coaster of birth, but also attempt to help navigate through the wreckage of past physical abuse. This role raises concerns that are considered in the fourth recurrent theme.

\section{Tensions and paradoxes}

The fourth theme, tensions and paradoxes, reflects on the wider issues that frame the nature of the care that the midwife can give, and the climate in which she must work. This theme highlights the legal framework in which such care is given and broader ethical considerations raised by midwives. All the participants within the study recounted in their stories an ethical dilemma when it came to choosing a course of action for the post-partum deinfibulated woman. Within the ethos of midwifery, one of the roles of the midwife is to facilitate informed decision by the woman, outlining the available options and implications to enable the women to make an informed choice. And yet as expressed by one midwife, 
leaving the woman deinfibulated ...we give women choice on everything else, then suddenly we are dictating what must happen. This is what I'm going to do and no I'm sorry but I can't stich you up afterwards, even though you have asked.

The reflections by the midwives turned on the ethical relativism that permeates their sphere of practice, by setting aside the normative values of their own culture they try to contemplate the woman's perspective.

Now I kind of just reflect within myself and think about it and try to put myself in their position and just try to see it as it is. This is their culture and this is how they do it and I can't impose my views.

Not withstanding the morality associated with the mutilation, the act itself is deeply embedded within the social values of the women. For the midwives the issues they must address with the women are deep rooted in culture, not what is right or wrong.

While contemplating their ethical concerns the midwives are also aware of the legal paradigm in which they must work. They acknowledge that this is something they must work within, yet the personal realities of the situations they experience challenge their resolve. As articulated by one midwife,

...we are doing our best to make it okay, within the confines of the law I guess...but the law is made by people who don't really have an understanding of what it is to be uplifted from one culture and stuffed into another.

Beyond the women they encounter who have experienced FGM type III, the midwives have concerns for the generations of women that they are bringing into the world and whether in spite of their efforts they might suffer a similar fate. For the midwife;

the challenges are catching female babies, and wondering what their future is.... 
The midwives struggle to establish trust with the women they attend who find themselves in an alien culture, such that they feel the need to threaten and cajole these women to protect the next generation. As stated by one midwife, she told them

not to do it to daughters' and has '...said to women in the past, if you do I will tell.

But a degree of ambiguity lies in the threat, as she goes on to say,

\section{I don't know who [I] would tell?}

This could be construed as an uncertainty as to the correct authority to report to. Or is it an act of civil disobedience for a law that risks driving a devastating practice underground and away from medical care. As implied by the statement of another midwife who asked

If I see it, do I report [it] because I know that in [the] law it's illegal...and where [do] I stand in that and my loyalties [to the woman]?

Within New Zealand society, much is made of the trauma of dealing with physical abuse. However, when the original abuse has been perpetrated outside our society, and the society in which it occurs does not perceive it as abuse, the triggers for structuring a full and supportive response in this country are lost. The themes arise as a consequence of those who intimately encounter an historic abuse, must deal with it, and must continue to perform their role with little or no support or guidance. What consideration is given to these midwives?

All of these themes highlight a lack of support structures accessible to the midwives to deal with the concerns that arise from their experiences of dealing with woman with Type III FGM. Although this issue is not specifically articulated by the midwives, a common thread running through all the themes is an absence of someone to guide them through the process, to prepare them for what they will encounter, or the provision of a safe framework in which to express the concerns and consequences of dealing first hand with the effects of mutilation, which has such severe physical and psychological effects. 


\section{Summary}

In telling their stories, the midwives reveal many different individual experiences and interpretations of events. These interpretations have raised many thoughts about practices, attitudes, expectations and values, which through reflection and repeated listening, have coalesced into four broad themes. Though these themes have been supported by quotes from the individual interviews, it is not intended to separate out different midwives views; rather it aims to identify the shared experience. This chapter opened with the true song, the distillation of those different midwives stories. Its intent was to convey the essence of the experience of those midwives without the focus on a particular individual's experience. It seeks to give resonance to all their experiences and enable those who have just begun their journey recognise their path.

In the following chapter it is intended that the issues within the true song that have been contained within the four themes, are examined and clarified to give greater insight into the experience of the midwife caring for women during the childbirth process, who have undergone Female Genital Mutilation Type III. 


\section{Chapter Five: Discussion}

This chapter elaborates on the key areas of the themes that are explicit within the true song and seeks to expand on them to add clarity to the understanding of the midwives stories. The key areas can be seen as distinct threads that are interwoven within the midwife's story. Their voices are revealed verbatim in the early part of this discussion chapter. The first of these key areas, the knowledge gap, reflects on the paucity of relevant information and education available to the midwives. This lack of knowledge exists, as a prelude to midwife's first exposure to caring for women who had FGM Type III, and carries through the consequences of attempting to partner the women across a cultural divide. It continues through the procedure of deinfibulation and its sequelae, and permeates the broader legal issues that shape the midwife's experience and the climate in which she must work.

The second key area, developing culturally safe care, focuses specifically on the ethical dimension that arises out of the necessity of the intervention of deinfibulation. This section considers the arguments for the choice of actions as a consequence of deinfibulation and offers a way forward through the shifting sands of cultural relativism.

\section{The Knowledge Gap}

The true song highlights the apparent lack of formal education for the midwives involved in this study regarding the care and management of women who have FGM Type III. This concern was expressed not only historically, as an absence of the topic in respect to the midwifery curriculum of the time, but also as a lack of contemporary educational opportunities as part of continuing professional development.

One cannot deduce from the information obtained in the study whether or not past or present midwifery educational curricula provide adequate information with regard to FGM. Three of the four participants were trained overseas more than twenty years ago. The fourth participant was trained within New Zealand within the last ten years. Recollection of past events, particularly after several decades, are likely to be 
unreliable at best, and no recollection of this topic in the curriculum does not in itself mean that the topic was not covered.

Further, as the time frame for the majority of the participants places their education in the period prior to the general awareness of the topic (prior to 1990), it would be entirely possible that little or no comment or training was provided on FGM. Irrespective of the situation at the time of training, all the midwives in the study group articulated an awareness of the topic. "I kind of had a general idea". It is considered that they, like many of the general population at the time, encountered reference to the topic as part of the general global awareness that occurred during the mid 1990s.

Although a lack of awareness, and therefore content in historical curriculum is understandable, it would be anticipated that some content would be present in contemporary midwifery curricula. As part of this research, all tertiary educational providers offering an undergraduate midwifery programme within New Zealand were contacted, and of those that responded, none were found to currently incorporate education about the appropriate care and management of women who have undergone FGM Type III.

The absence of any content within contemporary midwifery curriculum seems all the more remarkable in light of the national programme, that was established in 1998, to specifically address the lack of information regarding FGM and to highlight awareness within New Zealand. One of the participants in the research commented that what information they had gleaned was obtained from attending a regional workshop as part of this national programme. In spite of this the participant expressed that they still felt inadequately prepared for their initial experience.

Although, as mentioned by one of the participants of the study, a national programme was implemented in 1998, no follow-up or continuing support programme has been undertaken at a national level since that year. Auckland District Health Board has a contract for the education of refugees. Part of this programme incorporates health care for women who have undergone FGM. Regional District Health Boards can contract the service from Auckland Regional to have a training and education 
programme delivered on a needs request basis, (N. Denholm, personal communication, October 23, 2007).

The absence of an ongoing national programme and the lack of information pertaining to FGM forming part of the educational curriculum have left a vacuum in midwifery education around this topic. As a consequence midwives who did not participate in the regional workshops in 1998, or who have entered the midwifery profession within New Zealand since that year, have received no formal education in regard to appropriate protocols or procedures for women who have experienced FGM. Further, a comment from the participant of the study who had attended the national programme, suggests that a single exposure to the programme was inadequate in itself to prepare a midwife for the experience. "[I] attended a presentation...the stories, [that were] being told and how these women had undergone the procedure, it was all hard to hear and hard to listen to". Yet no further national programmes have been implemented, although the number of female African Refugees entering New Zealand, and therefore the chance of encountering a woman with FGM Type III in midwifery practice, has increased substantially since 1998.

It is interesting to note that while FGM Type III received a high media profile in New Zealand in the years immediately preceding and up to 1998, as it did globally, the New Zealand profile faded rapidly after this date. This lack of profile for FGM Type III in New Zealand is reflected in the lack of literature published in New Zealand pertaining to FGM as highlighted in the literature review presented in Chapter Two earlier in this study. This is contrary to the global trend, which has sustained interest to the present day in this topic.

To legislate but not continue to promulgate education on an issue that touches at the very heart of human rights is a flaw in New Zealand's midwifery education system. A clear need exists for an ongoing evidence based national educational programme, that provides appropriate training for midwives and other clinicians (undergraduate and post graduate) on the nature, impact, issues and appropriate management of care and delivery for women who have undergone FGM Type III. From the midwife's 
perspective, this lack of knowledge introduced unnecessary levels of uncertainty and concern over appropriate practice and management of women with FGM Type III.

\section{Developing Culturally Safe Care}

For the midwife caring for women who have FGM Type III, perhaps the most pervasive difficulty is the perceived barriers that arise from a lack of cultural understanding. The lack of knowledge in regard to the correct procedures, protocols and practices often manifests itself as a hypersensitivity to the potential to cause cultural offence, reducing the midwife to inaction in the face of uncertainty. "How was I going to approach her culture in a way that was safe for her, but also safe for me”?

This can be seen in one of the fundamental issues that confront the midwife early in their role as primary caregiver, that of determining if in fact the woman has undergone FGM. Not only is raising the topic of FGM fraught with cultural sensitivities, but it also assumes that the women themselves are aware of the distinction. This requires that the women be in a position to determine that they have been subjected to a trauma that does not occur for all women. That such a traumatic event could or could not have occurred without the victim's knowledge is not in question, but rather that women recognise that what has occurred is distinctively different from the cultural norm of the country they now find themselves in, and that they are aware of the significance of this difference.

The assumption that one is aware of one's own body is culturally determined. By comparison to many African and Middle Eastern societies, Western society is more sexualised and nakedness is in the public domain. By contrast, for the communities in which FGM is practiced, women would not expose their genitalia even to their partners during sexual intercourse. Nor would they inspect their own genitalia with a mirror or have published images of genitalia from which to gain a comparison (Odujinrin et al., 1989). As a consequence, such women may have a poor understanding of what FGM Type III actually involves. In one study of female circumcision, for example, Odujinrin et al. found that almost a quarter of the women 
who had claimed to be circumcised were found to be uncircumcised on medical examination. For the midwife, an approach, which allows for candid discussion, without the concern of causing cultural offence is required.

According to Momoh (2005) it is advantageous for midwives to ask, as part of routine antenatal care, if they have been circumcised ('circumcision' being considered a less emotive, although technically incorrect, word within this context). Rymer and Momoh (2005) suggest that this should be put carefully but directly; they suggest that a good lead question would be 'I understand that female circumcision is usual in your country, have you been cut down there?' When a woman has been infibulated, the role of the midwife is to explain why deinfibulation is necessary, and why she cannot be re-stitched due to negative/harmful women health issues and that it is illegal to do so in New Zealand. This may instigate the woman to consider antenatal deinfibulation. Early antenatal deinfibulation is recommended rather than performing the procedure at the time of delivery. If the midwife is not familiar with the culture, however, then the necessary question regarding ‘circumcision’ will remain unasked.

Although the midwives in the study did not mention that they asked this question, it does not necessarily mean that they did not raise the issue. However, in light of the difficulty expressed in regard to other cross-cultural approaches, it would be consistent to discover that this had not been considered. For the midwives within the study, the issue of broaching even fundamental medical questions became stymied in the mire of confused cultural sensitivity. Questions, which are clearly known to have a cross-cultural dimension, are even more susceptible to inaction due to this confusion.

Within the New Zealand context the role of the midwife when caring for women who have undergone FGM in childhood, revolves around the childbearing process. However, the midwife also encounters the long-term health complications that the procedure entails. The general health implications are well documented and there is reliable evidence about its harmful effects on gynaecological and reproductive outcomes, and the increased chance of maternal and child mortality (Cameron and Rawlings-Anderson 2001). It comes as no surprise, that in terms of their physical health, it is considered better for the women to be deinfibulated. 


\section{Undoing the harm}

In the midwife's experience, the act of deinfibulation could be considered the pivotal procedure in terms of caring for a woman with FGM Type III. Deinfibulation is undertaken by performing an anterior episiotomy where the labial remnants are separated. The primary intent behind deinfibulation, as performed by midwives, is the creation of an opening of sufficient size to enable the safe delivery of the baby.

According to Newman (1996) performing an anterior episiotomy to open up infibulation would be necessary, to facilitate the safe delivery of a baby. If not carried out, excessive tearing or intrauterine death may result. For the midwife, the act of deinfibulation is seen as an inevitable sequelae to infibulation and required to facilitate a safe delivery while reducing possible medical complications.

\section{Ignorance or avoidance}

As conveyed in the midwives stories, it was apparent that some practitioners' attempted to circumvent the issues associated with deinfibulation by undertaking posterior episiotomies. (The term practitioner is now used, as it is not always the midwife working in isolation, but often calling upon a doctor for assistance). It is unclear whether the main motivation for this course of action was through ill informed medical advice, or an attempt to avoid the ethical dilemma that the procedure of deinfibulation invokes. The medical and ethical arguments against this rationale are outlined in the following two sections.

\section{The medical argument against posterior episiotomy}

For many years the practice of routine episiotomies to assist general deliveries was supported, due to the common belief that the perineum could act as a potential barrier to the descending foetal head, and that a vaginal birth would lead to pelvic floor dysfunction later in life (Thacker and Bantu, 1983). Supporters of the procedure believed that all of these complications could be avoided by performing an elective

episiotomy. This was challenged by the seminal research randomised controlled trials, which identified that elective episiotomies did not avoid these complications and there were no increased benefits as a result (Sleep and Grant, 1987). 
As expressed in the interviews, some midwives and doctors address the infibulated state by solely performing a posterior episiotomy, although it should not be a routine procedure (Dahlen et al., 1999). Posterior episiotomies alone are inappropriate for infibulated women as it is likely that the anterior scar will tear or rupture, due to the rigidity. Depending upon the scar tissue around the introitus and the lack of stretchability of the tissue anteriorly, then performing a mediolateral episiotomy is justified. According to evidence-based practice, for the midwife caring for women with FGM Type III there is no justification for the use of posterior episiotomies as an alternative to deinfibulation (Neman, 1996; Dahlen et al., 1999; Cameron \& Rawlings-Anderson, 2001; Parkin, 2001). Therefore, over two decades later, why are midwives appearing to be reverting to unnecessary practice?

\section{The ethical argument against posterior episiotomy}

As identified in the interviews, some midwives (and other practitioners) attempt to circumvent the legal complications by undertaking posterior episiotomies. The argument for utilising a posterior episiotomy to avoid the ethical implications of deinfibulation and its consequences is jejune at best. It proceeds on the basis that if a delivery can be achieved without affecting the infibulated state, then the discussion pertaining to deinfibulation or otherwise is moot. Putting aside the long-term health implications for women with Type III FGM, it assumes that the cutting of otherwise healthy tissue is an acceptable alternative. Following this line of argument reductio ad absurdum, caesarean is as an acceptable option as posterior episiotomy.

This line of reasoning is flawed; as it fails to consider the Hippocratic dictate, first do no harm, which should apply to all practitioners within the health domain. Even though the woman is infibulated, the birthing canal remains intact. Deinfibulation is a corrective procedure of mutilated tissue, which reinstates the birth canal opening. It does not require the cutting of any other tissue. By contrast, as stated by Cameron and Rawlings-Anderson (2001), if mutilation implies injury without conferring any benefit, then use of posterior episiotomy can be considered a form of genital mutilation. 
From an ethical perspective, the use of posterior episiotomies as an avoidance strategy simply exchanges one harm for another. For the midwife caring for women with FGM Type III, the ethical argument becomes not one of avoiding confrontation and doing no harm, to one of avoiding confrontation through the mutilation of healthy tissue. When phrased in this manner, ethically, this avoidance strategy is not a conscionable option.

For the midwife, the act of deinfibulation is necessary for the care of women with FGM Type III. The procedure itself is uncomplicated, but the consequences of the procedure have ramifications that require a clear understanding of both practice and ethics. When deinfibulation is approached in this manner it can be interpreted as a healing procedure that addresses some of the physiological complications of infibulation. It is the attempts to avoid confronting the practical and ethical realities of the deinfibulation that result in the most harm.

\section{The re-traumatisation}

One of the harrowing implications of deinfibulation was related by the midwives in their interviews and expressed in the true song, whereby memories of the primary FGM appear to be reawakened for the woman in the labour and birth situation. This was highlighted in the midwife's story, with women manifesting a form of posttraumatic distress, becoming unresponsive and disassociated. This reawakening is also captured by Toubia (1995), who states; 'for those with the severest form of FGM, infibulation, the trauma of mutilation is repeated with each childbirth' (p.5). Dahlen, Nanayakkara and Bullivant (1999), go so far as to recommend that stirrups not be used, as the restriction may contribute to flashbacks of being restrained as a child for the original FGM procedure. As with all traumatic events, the ramifications are myriad and propagate throughout the life span of the individual involved and all those with whom they interact. This is no less true for midwives who, due to their profession, must vicariously experience the traumatisation, intimately and repeatedly.

Within the New Zealand context, of critical importance for the midwife caring for women with FGM Type III, is that once deinfibulated, New Zealand law dictates that the woman must remain deinfibulated. Although the midwife is well versed in the 
significant health benefits of leaving the woman deinfibulated, it was not always as readily perceived as being in the best interests of the woman by the woman, her family and within her culture. As identified in the study, frequently social pressure is placed on the midwife to reinfibulate. The issue of conflicting benefits and consequences warrants further elaboration and the cross-cultural debate over deinfibulation are discussed in greater detail later in this chapter.

\section{The legal framework}

Although the adverse effects of FGM have been documented by women's organizations, health professionals and human rights campaigners for years, serious attention to this practice by governments gathered momentum in the mid 1990s. Since that time, support for the elimination of FGM gained increasing recognition as a health and human rights issue among governments, the international community, and amongst health professionals. As a result of concerted efforts by individuals, non-governmental organizations, The United Nations and World Health Organization began to lead the way in global awareness of FGM.

The cruelty of the practice and the lack of any physical benefit to those subjected to it, resulted in the practice being clearly recognised as a violation of human rights and legislated against by the WHO (1997). Most western countries followed suit, making the practice of FGM illegal.

In recognition of the high profile and universal condemnation of FGM globally, New Zealand incorporated an amendment to the New Zealand Crimes Act 1961 specifically pertaining to FGM, making the perpetuation of the practice illegal.

Section 204A Female Genital Mutilation, Subsection (1) has been discussed at length earlier within chapter two. Under section 204a, the act of FGM is illegal irrespective of whether or not it is undertaken with the consent of the person on whom the act was performed. A lack of awareness of the fact, that consent or otherwise does not repudiate the illegality of the act, is made explicitly in subsection (6). 
Of importance for the midwife in evaluating the consequences of her involvement with women who have undergone Type III FGM, as previously discussed in regard to bioethical considerations, the argument for considering the non act as potentially as harmful as the act of FGM, balancing beneficence with maleficence, is specifically excluded as a potential argument. Subsection (4) of the act is specifically tailored to remove this line of arguing by stating that cultural, religious or other custom or practice cannot be included in this instance when evaluating the benefit to the individual.

Of further concern for the midwife under subsection (1) is the definition of female genital mutilation; the terms excision, infibulation and mutilation are used disjunctively. That is, should any one of these acts be performed in isolation, then it constitutes the definition of female genital mutilation, is illegal, and the perpetrator is liable for the imprisonment term. The term reinfibulation is not specifically used in the context of the act. However the application of the prefix does not obscure its meaning. The act leaves no reason or justification for undertaking infibulation whether for the first time or as a subsequent 'reinstatement' procedure. To do so under New Zealand law is illegal and remains so even if it is compliant with the women's wishes.

\section{Filling the gap}

In one sense the knowledge gap is the heart of the problem. For without it, many of the issues that are the genesis of the subsequent stages would simply not occur, or at the very least, their effect be greatly reduced. With appropriate knowledge many of the cultural misgivings would not occur, a greater level of understanding would prevail and expectations would be more clearly understood. With appropriate knowledge some of the trauma of deinfibulation would be reduced and an understanding of the physiological benefits of the deinfibulated state would assist with its acceptance by the individual and the culture. With appropriate knowledge correct procedures and options would be undertaken compliant with the law. And finally, with appropriate knowledge the educational framework would exist to instil this knowledge and assist the midwife through the experience of caring for women with FGM Type III. 
The preceding discussion clarifies the issues faced by the midwife when confronted with the need to care for women during childbirth who have undergone FGM Type III, and the implications and pressures exerted on them to choose from the range of medical procedures both during and after the delivery. They have identified the range of consequences these choices have, which extend beyond the immediate participants involved in the procedures and the legal framework in which these actions must be taken. However no consideration has been given to the ethical framework in which these actions are performed, and for whom they are determined as being 'right' or 'for the best'.

When considering matters of an ethical dimension, empirical reflection is inadequate. One cannot assume that the dominant society is right; to quote an old adage, 'the highway to hell is paved with good intentions'. Complex though it may be, the ethical dimension lies at the heart of the experience of the midwife caring for women with FGM Type III, and it is to this matter we now turn.

\section{Cultural Conflict}

All the participants within the study recount in their stories an ethical dilemma when it came to choosing a course of action for the post-partum deinfibulated woman. An ethical dilemma arises because, having once deinfibulated the women to facilitate birth, then any course of action, to reinfibulate/infibulate or not, results in detrimental consequences for the women. The difficulty for the midwife is choosing which is the best course of action when there are conflicting values to be assessed.

According to Cameron and Rawlings-Anderson (2001),

"[b]ioethics facilitates the systematic analysis of difficult questions or situations in health care where there are conflicting values....[it considers] factors such as lifestyle, nutrition and social factors ....[using] the principles of autonomy, justice, beneficence and non maleficence and applies them to specific situations” (p.231). 


\section{Describing the cultural context for FGM.}

To be able to evaluate the dilemma for the midwife caring for women during the childbirth experience who have undergone FGM Type III, from a bioethical perspective, one needs to understand the cultural context, which resulted in the specific situation. The notion of culture was introduced in chapter two, along with the concept of cultural relativism and the potential pitfall of moral imperialism. Yet to evaluate this dilemma one must go beyond ones own culture and attempt to reflect on the activities and behaviours in the culture in which they occur.

Although one may not have total understanding of the motivations behind an alternate culture, a degree of understanding is still possible without the pitfalls of moral imperialism. There are some values that are consistent throughout all cultures. Rights that are fundamental to the individual are logically prior to rights that are fundamental to society, however the two are inextricably linked. It is through the commonality of these universal values that one attains a transcultural perspective. From this perspective, bioethics can be used to consider the differing stances surrounding the practice, in determining the response of health care professionals and society, and discouraging cultural imperialism (James, 1994; Baker, 1997). It is this transcultural perspective that the midwife must strive to attain. As stated by Cortis (2004), midwives need to be prepared for the challenge of being 'with multicultural women' and be better educated about diverse faiths, beliefs, cultures and practices.

In order to evaluate deinfibulation the midwife must have a sense of the motivation behind the practice of FGM. In cultures where the practice of FGM is prevalent, the submission to this practice is often seen as a right of passage to womanhood. The submission to the practice of FGM affects the girl child /woman's social status, value in society and consequently their potential survival. The practice is so entrenched within some cultures that it has become the norm (Rouzi and Aljhadali, 2001). The act of deinfibulation, cutting through scar tissue to widen the vaginal opening, changes them physically and emotionally. They no longer appear the same and may feel that they have been surgically violated. The deinfibulated state, whilst necessary for the birth process, if left 'undone', also carries with it social and psychological stigma. 


\section{Autonomy for the woman}

If midwife is able to attain the transcultural perspective then different issues pertaining to FGM begin to shift into focus. One of the principles of Bioethics is that of autonomy, that is the woman's right to self-determination. According to Downie and Calman (1994), "to be an autonomous person is to have the ability to be able to choose for oneself or more extensively to be able to formulate and carry out one's own plans or policies” (p.52). Clearly certain criteria must prevail if autonomy is to be obtained, that being the woman is competent, informed and the decision voluntary.

Not withstanding the existence of these criteria, in light of the principle of autonomy, if a midwife, having deinfibulated a woman, is then requested to resuture should that request be honoured? What is being questioned is the woman's autonomy, her right of self-determination, the rights of a woman over her own body, even if those rights relate to the cultural beliefs of minority groups which do not correspond with the overriding cultural paradigm? For the midwives caring for women with FGM Type III, the question becomes one of; 'do they have the right to impose the surrender of a practice because it does not concur with the dominant culture paradigm’?

Leininger (1984) defines this as cultural imposition. Women have the right to expect from midwives that they will be their advocates by doing what is best for them. When a midwife imposes her values upon a client without considering the client's own values, feelings and beliefs this could be considered as racist, according to Black and Debelle (1995) as it entails the prohibition of the customs and traditions of an ethnic group. This sentiment is echoed by MacPherson (1999), who states that 'unwitting' racism and discrimination is caused by ignorance and thoughtlessness. For Ramsden (1995), this cultural imposition reflected the origins of the British tradition, with medical training being derived from military culture and inherited the military culture. "In those days a 'one size' service was intended to fit all. The condition was nursed rather than the person” (p. 7). 
Leininger (1978) identified the need for [midwives] to become more familiar with diverse cultures as societies are becoming more multicultural and a greater understanding of different cultures allows for a better standard of care. This same rationale applies for all health professionals. In the present climate of professional accountability, the appeal to ignorance and thoughtlessness as a defence of discrimination is not acceptable. It is crucial that midwives broaden their own knowledge base creating an awareness of different cultural beliefs so as to become non-judgemental.

The lack of knowledge by midwives, as highlighted within the study, could be seen as being culturally unsafe. As stated by Srivastava (1996) "if midwives are to effectively deal with the issue of FGM, it is not enough to merely develop a cultural awareness of this subject; one must go further and develop cultural competency” (p.190). Ramsden (1995) goes further when she states that cultural safety insists that... "midwives become experts in understanding their own diversity within their own cultural outlines as well as their potential for powerful impact on any person who differs in anyway at all from themselves” (p.8).

If a midwife deinfibulated at the time of delivery and did not resuture if requested by the woman, then she is not allowing the woman full autonomy. But the notion of autonomy is balanced by the principles of beneficence and non-maleficence: Nonmaleficence; a moral principle ('above all, to do no harm') and beneficence; (above all, to do good).

\section{Beneficence and non-maleficence}

For the midwife, having deinfibulated, the principle of beneficence would seem to support the decision not to re-suture. As stated by James (1994) the "negative health effects of the procedure far outweigh the supposed benefits"(p.24). Within the principle of beneficence we have a moral duty to consider the relationship between harm and benefit, not only for the individual but also for the wider society. The potential benefits to the wider society, from health issues and costs, are more diffuse and relate to the absence of greater economic encumbrance upon society. Since the act of deinfibulation and not re-suturing may be seen as a way of the dominant culture 
allowing entry into society because it would harm the individual to be excluded from the society (Beauchamp \& Childress, 1994).

However the decision by the midwife to not re-suture may ostracise the woman from her own culture. Has the midwife conformed to the principle of non-maleficence? As stated by Beauchamp and Childress, (1994), the "obligations of non-maleficence are more stringent than obligations of beneficence”(p.191). Further, if the individual's cultural perception of perfection is to be infibulated, what state have they now been rendered to? It could be argued that midwives have violated the bodily integrity of women and informed consent of their clients in order to maintain their cultural value. Within the cultural paradigm of the woman, being left in a deinfibulated state could be interpreted as mutilation.

The notion of mutilation warrants further investigation, as it too is culturally determined. According to the Oxford Dictionary (1990) to mutilate, is to, 'deprive (a person) of a limb or organ. Destroy the use of (a limb or organ). Render imperfect by excision or some act of destruction'. Is it then any wonder that post deinfibulation women frequently request to be reinfibulated? Outside their culture the infibulated state may be considered abhorrent, but the perception of an individual is from within their own cultural framework. This is exactly the point Webb (1995), raises when he asks whether we should question and prevent a cultural practice if it is acceptable within that culture. The failure to reinfibulate cannot be a non-maleficent act if it is inherently harmful to the woman who has been deinfibulated.

Further, in the event of having performed deinfibulation and refusing to 'stitch me back-up as I was', does the midwife run the risk of driving the woman to find alternate and illicit assistance to be re-sutured? And by this failure to act, contrary to the spoken intention of the woman, do we not become the indirect agents of the harm? This raises the question of in whose interest is it to leave a woman deinfibulated if the goal is to minimise harm given the potential harm presented by illicit treatment. Leininger (1990) criticises ethicists for their failure to recognise the important and significant role that culture plays in guiding moral judgment and behaviour. 
One line of argument open to the midwife centres on the claim that there is no cultural imperative that would require resuturing to be undertaken. The argument follows the line that as there is no Koranic basis for ...[FGM]... as one of the supports for its practice. (It dates to before Islam, and is suggested by Black and Debelle (1995) that it preserved the monogamistic status of women). The belief that Mohammed advocated the procedure cannot be sustained and therefore there is no justification for resuturing to maintain the infibulated state on religious grounds, as there was never a religious imperative to begin with. This line of reasoning fails as it attempts to rationalise the practice out of existence, without considering the sociological bottom line that the practice is already entrenched within the culture.

From the midwife's perspective, when declining to reinfibulate they must consider whether they have the right to take away something that is woven into the very fabric of a culture. In the case of the midwives clients, this issue may be construed to have greater significance, as it is often the only thing that is carried with them from their homeland. Their cultural translocation results in a sociological phenomenon whereby the translocated culture clings more rigorously to the cultural mores of their homeland, often fixing them at the time of their translocation. Therefore, one could argue that possibly where the translocation of a culture has occurred, greater significance should be placed on the practices that embody that culture. According to Sherratt (1999) "health care for refugees and displaced persons are perhaps the most pressing concerns for research and innovations by midwives at the turn of the millennium” (p.64).

For the midwife caring for women with FGM Type III, the bioethical perspective offers some useful insights. From a purely bioethical perspective, in terms of the autonomy, beneficence and non-maleficence, the case for and against re-suturing seems to swing toward allowing resuturing should the woman request it. The main argument against it is based on the anticipated health consequences that this action may have. However this dilemma is unresolved. While the benefit to the larger community is indirect and diffuse, with a greater or lesser burden resting on the medical state, the individual carries the direct burden in terms of health consequences, both psychological and physiological. 
To provide a clear resolution to the dilemma, one must defer to the legal framework in which the midwife works. The legal framework excludes the consideration of psychological consequences from the evaluation of beneficence and therefore requires the deinfibulated state to remain.

\section{Summary}

This discussion chapter has explored the issues raised by the experience of midwives caring for women who have undergone FGM Type III during the childbirth experience, as highlighted in the true song. The midwives experience has raised the distinction between the lack of theoretical knowledge as discussed (educationally, medically, culturally and legally), the resulting practical responses, and the varying shades of grey that exists between them. It has considered the ethical quagmire that surrounds cross cultural issues where the utility of any procedure must be counter pointed with the question; 'Best for whom?'. It has presented a number of considered responses and arguments for the ethical questions, which have been posed.

Caring for women who have undergone FGM Type III during the childbirth process, poses highly unique problems, which require midwives to have a wide range of skills including being an advocator, educator and cultural liaison. For the midwife, when considered individually the issues surrounding the care of women who have undergone FGM Type III are complex and may appear unresolved in isolation. However, the final determination cannot be misinterpreted. Deinfibulation must be performed appropriately and the deinfibulated state must be maintained. The challenge for the midwife is to cultivate an understanding of the culture in which FGM occurs and seek to find an approach, which conveys the necessity and benefits of deinfibulation without falling into the pitfalls of moral imperialism. 


\section{Chapter Six: Conclusion and Recommendations}

This interpretive study has sought to shed light on 'the experience of caring for women during the childbirth process, who have undergone Female Genital Mutilation Type III', through a small group of midwives telling their stories. The principles of qualitative design using narrative inquiry methodology were employed in the writing of the study.

Using narrative inquiry, the stories of the women were distilled and combined to create the essence of the experience, the true song. Through this iterative process the identification of common themes and issues encountered by these midwives were revealed and brought to the fore. These themes and issues were within the true song, but through listening more attentively they were heard more clearly. They were not extracted and listened to separately, as it is only through their counterpoint with the other voices within the true song that their essence can truly be assessed. It is this contextual component, the extent to which the individual events are embedded within the whole of the story which gives narrative inquiry its power to clarify experience.

\section{Meeting the research aims}

The aim of this research was to explore the experience of midwives working with women during the childbirth process, who have undergone Female Genital Mutilation Type III. It was anticipated that if midwives recounted their stories of being in this situation, analysis of these stories would illuminate the experiences of these midwives, their challenges and dilemmas, and how they arose, how the midwives responded to them and the emotional consequences their responses entailed. These research aims were encapsulated by the following objectives to:

- Capture the story of a small group of midwives who have cared for women, during the childbirth experience, who have undergone Female Genital Mutilation (FGM) Type III.

- Uncover and explore, issues that midwives may have encountered in providing care for these women. 
Four midwives were recruited as participants and interviewed, using the principles of qualitative research. Their interviews were analysed and reviewed using narrative inquiry methodology to produce the true song, a distillation of the experiences of the participants' stories. This process enabled the identification of a number of themes and issues that were intrinsic to the experiences recounted by the midwives. These issues were identified in the findings chapter and further explored as two distinct threads within the weave of the true song. These two threads, the knowledge gap and the developing culturally safe care, were teased out more fully within the discussion chapter.

The research highlighted two areas of concern for the midwife caring for women with FGM. The first of these related to a lack of specific knowledge concerning the care of women with FGM. For the midwives this extended through the duration of the experience, from the initial exposure to the phenomenon, through the first personal experience, and continued up to and was expressed in the interview in which they recounted their stories. This lack of knowledge concerned the midwifery care and management of women with FGM, the opportunity for the midwife to review what knowledge they had gleaned within a safe environment, and to have a channel for expanding the knowledge base they had acquired. It also concerned the lack of knowledge about appropriate cultural guidelines and expected behaviours within a cross-cultural setting. And finally it concerned a lack of knowledge regarding the legislative framework within New Zealand in which the midwives carried out their practice.

The second area of concern for the midwife related to ethical dimension of the act of deinfibulation from the midwife's perspective. How, as a midwife in partnership with a woman, they can and must undertake to commit to a practice that seems to contravene one of the fundamental building blocks of partnership, by not following the wishes of the woman. And by what process they can reconcile themselves to this position.

The components of the midwife /woman partnership is inculcated in Standard One and Standard Two of the Midwifery Standards for Practice (NZCOM, 2005) and 
define the nature of the partnership. Yet the legal framework within New Zealand requires that aspects of that partnership must be subsumed which creates tensions and paradoxes for the midwife, not least of which is the continuing validity of the notion of partnership in this context. The discussion on ethical issues opens a Pandora's box for the midwife and although some of the complexities of the issue have begun to be unravelled here, there is a need for continued exploration and dialogue.

\section{Recommendations}

This study highlighted a number of shortcomings within the present midwifery educational curriculum in regard to the care and management of women with FGM Type III. These include recommendations both for the women who have suffered the trauma of FGM and the midwives who must confront the consequences:

- Comprehensive National Guidelines on caring for women, gynaecologically and obstetrically, who have undergone Female Genital Mutilation (regardless of type of mutilation) should be mandated by the Ministry of Health and implemented at the District Health Board (DHB) level.

- A nationally accessible resource should be developed, that would facilitate the dissemination of knowledge to midwives and other health professionals, who could be exposed to women who have undergone this procedure.

- On-going regular national programmes of education should occur. A designated liaison midwife should exist to coordinate regional programmes and be available to provide professional support and guidance.

- The development of a DHB based Mentor programme between experienced midwives and those who are caring for or wish to care for women with FGM. This programme should allow the midwives to educate and support one another by reflection one on one, or in groups. This should include access to counselling for the midwives. 
- Antenatal screening of women from countries that are identified by the World Health Organization, as having a prevalence of Female Genital Mutilation should exist. This could take the form of a simple 'tick box' sheet that would have a dual purpose. Firstly, it is a timely process to highlight to the midwife the need to put in place appropriate care and management throughout their clients pregnancy, which would include ongoing sensitive discussions and an early referral to a female specialist. This may include antenatal deinfibulation. Secondly, this information in part could be transferable to a health system database that would collate accurate data on the health of these women, not only physically, gynaecological and obstetrically, but also psychological to assist in providing holistic support for these women through other health professionals and support agencies.

- The development of a language resource including female interpreters and resources: e.g. books, videos and pamphlets. Midwives need efficient communication; verbal and written in order to support the women and families in their care.

- Networks need to be developed, working with key members of communities in which FGM occurs.

This research study has highlighted several areas of concern for midwives when caring for women during the childbirth process who have undergone FGM Type III. There exists a lack of consistent theoretical and practical knowledge among midwives, which has widened since 1998 due to a lack of educational support and collegial isolation. This topic should be introduced into undergraduate midwifery programmes and taught by an educator who has the appropriate knowledge base and skill. Opportunities need to be made for practicing midwives to attend in-service, post-graduate conferences, workshops and study days on this important topic, to safeguard practice and expand the understanding of midwifery specifically with regard this matter and the wider issues surrounding it. This initiative would be supported by the College of Midwives. 


\section{Further research}

A number of the initial themes identified in the true song could be taken and explored further. Research into the efficacy of existing midwifery education in terms of continued professional development and specialist topics seems warranted.

Qualitative studies which focus upon the woman's perception of their experience of care by the midwife, and the women's lived experience of having undergone Female Genital Mutilation would be valuable companion studies for this research and assist in identifying beneficial changes in the approach to care.

As so little research has been undertaken into the New Zealand situation, the plethora of women's health issues that follow on from the consequence of Female Genital Mutilation and to what extent they are manifest and treated (e.g. infertility, pelvic inflammatory disease, mental health as a result of post-traumatic stress and the complications of living as a refugee within New Zealand and accessing women health services) would provide instructive background investigation.

In addition this study has touched on the ethical dimensions of midwifery; what it means for the practitioner and how it is applied in reality. This area warrants further research, as it is a complex area that continues to grow as globalisation shrinks the distance between the communities encountered. A very real need exists for midwives to have accessible workable knowledge and support in this area particularly due to the autonomous practice model of midwifery care in New Zealand.

\section{Final comments}

It is hoped that this study has generated knowledge for practice from practice. Midwives consistently strive to give women, their babies and families a safe and positive childbirth experience. This wealth of experience is an overlooked source of knowledge. Midwives must listen, write and hear each other's stories from practice. The uniqueness of New Zealand midwifery, and how it is practiced, offers midwives the opportunity to steer head the formulation of evidence-based guidelines for women 
who have undergone FGM. These could include guidelines for antenatal, intrapartum and postnatal care and management.

This research has sought to shed light on midwives' experiences caring for women during the childbirth process, who have undergone Female Genital Mutilation Type III. Listening to the stories of four midwives has created new understanding about their experiences and concerns. It has highlighted the similarity of those experiences in spite of the variability of the context that surrounds them. Indeed it has highlighted that, although many of the elements that comprise the context are varied, the resulting situations have a resonance that are remarkably consistent across the participants. The essence of the true song lies in the distillation of the experience that is familiar and yet particular. 


\section{Appendix A}

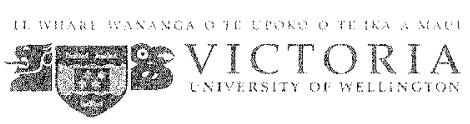

Information for potential participants of a research study

\section{Title of study}

An interpretative study of the experience of midwives caring for women during the childbirth process who had previously undergone Female Genital Mutilation Type III.

Dear midwifery colleague,

My name is Annette Garvey-Graham and I am enrolled in the Masters of Midwifery programme at Victoria University of Wellington, undertaking this research as part of my final year of study. The Human Ethics Committec, Victoria University of Wellington, has approved this research study.

As a midwife practitioner I have travelled the world experiencing different midwifery practices and worked in a variety of settings.

My first exposure to the practice of Female Genital Mutilation and caring for women who have undergone this procedure occurred many years ago whilst working in the African sub-continent. In recent years in New Zealand, I have once again been exposed to women who have previously undergone Female Genital Mutilation Type III (F.G.M.). This has prompted my research interest.

The World Health Organization (WHO, 1997) defines female genital mutilation as: 'all procedures involving partial or total removal of the external female genitalia or other injury to the female genital organs whether for cultural or other non-therapeutic purposes'. Type III FGM is where there is 'excision of part or all of the external genitalia and stitching/narrowing of the vaginal opening (infibulation)'.

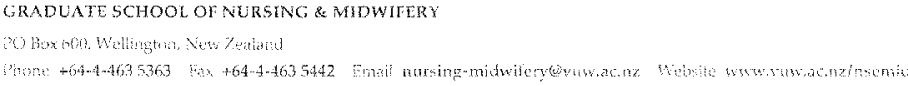


The purpose of this study is to gather descriptions from midwives about their feelings and experiences of caring for women who have previously undergone FGM Type III. The particular focus of this study will be on those feelings and experiences during the process of labour and birth.

While a wealth of information exists around the FGM procedure itself and the legislation regarding it, nothing has been specifically documented about the midwives' experiences of caring for women who have undergone this procedure. This research seeks to initiate investigation into this area.

The study recognises that there are many different possible interpretations with midwives 'telling their story'. It is anticipated that these interpretations will raise many thoughts about practices, attitudes, expectations and values. This study does not wish to separate out different midwives views; rather it aims to identify the shared themes.

If you agree to participate in this research, I would interview you for the purpose of describing your experience of caring for women during the childbirth process that had previously undergone Female Genital Mutilation Type III. To achieve rigour in the research process, the conversations will be audio taped, and later transcribed. Your participation will be confidential and pseudonyms will be used to maintain your anonymity. The tapes remain confidential to the thesis supervisor and me.

The interview will take place in an environment that is private, convenient, and agreed on by us both. It is likely to last approximately an hour. You will later be given a copy of the transcript of the interview and will be free to delete any parts of the transcript that you do not wish to be part of the research study. Should either of us decide that aspects contained within the transcripts warrant further discussion, then a second interview could be arranged. Again, you will be invited to review the transcript and delete or amend any parts that you do not wish to be included. 
This data will form the basis for comparison, analysis and interpretation from which the commonalities of the experience will be uncovered. A summary of the work will be sent to you on completion.

The research report will contain direct quotations from the transcripts. This is to validate the interpretations that are made. An example you give to describe a particular point may be used in full. It is from such stories that the reader is able to relate their own experience and perhaps reach a new understanding.

It is important to remember that the purpose of this study is to find meaning, not to judge individual practice or situations. My role is not to agree, or disagree. I am there only to hear the descriptions, and to work with you in teasing out the meaning.

If you would like to discuss this further, or if you are willing to participate, please contact me on 0276571567 or my supervisor, Dr Joan Skinner, at the Graduate School of Nursing, Midwifery and Health at Victoria University, PO Box 600, Wellington, phone 0800108005 .

Thankyou for your consideration

Annette Garvey-Graham

Midwife 


\section{Appendix B}

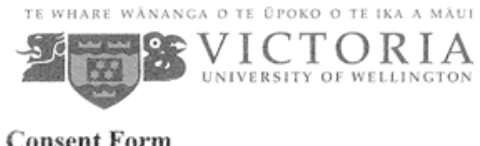

\section{Consent Form}

I have read the information sheet for this study and have had the opportunity to seek further information. I understand I may ask questions at any time.

I also understand that I am free to decline to answer any particular questions in the study, or withdraw from this study up to three months from the date of the interview. I agree to provide information to the researcher on the understanding that it is completely confidential.

I wish to participate in this study under the conditions set out on the Information Sheet, of which I have a copy.

Name of participant.

Signature of participant

Date.

GRADUATE SCHOOL OF NURSING, MIDWIFERY \& HEALTH

PO Box 600, Wellington, New Zealand

Phone +64-4-4635363 Fax +64-4-4635442 Email nmhevuw.ac.nz Website www.vuw.ac.nz/nmh 


\section{Appendix C}

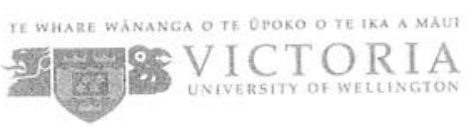

\section{Confidentiality Contract for Transcriber}

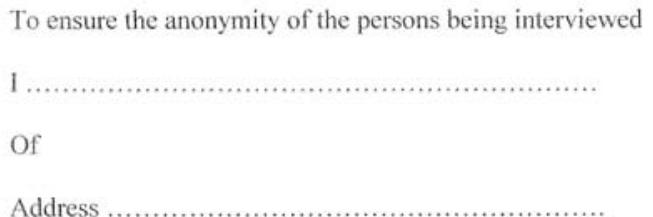

Declare that I will not divulge any information gained from the transcripts I produce for the researcher, Annette Garvey-Graham.

Signature

Date

Researcher Annette Garvey-Graham

Signature

Date 


\section{Appendix D}

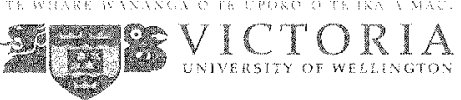

Return of Transcripts

Dear

Enclosed is the transcription of the interview conducted on

Other than an independent transcriber who signed a confidentiality contract, no one else has seen this script. The text is secure on my computer which requires a password for access purposes. The digital audio tape from which the transcription was made is securely locked away in a filing cabinet.

The transcription is verbatim, including fillers, (umms and ahhs). Because it is raw data, it does not have the refinements of written language. Instead, it conforms to the natural rhythms of conversation, and so may seem incoherent in places. When stories are being developed from raw data, information will be altered to better reflect both story and writing conventions.

I would appreciate you reading the transcript and adding, deleting or altering any parts you wish. Please make comments on the transcript itself, and return it by mail, with the accompanying form releasing the transcript for use.

If you have named particular people that are relevant to a story that develops, you may choose a pseudonym to protect their privacy. You can indicate this on the transcript.

If you would like to discuss the transcript prior to returning it, please feel free to contact me.

I look forward to receiving your responses and the accompanying form. If I have not received this release form after two weeks, I will telephone you.

Regards,

Annette Garvey-Graham.

Midwife

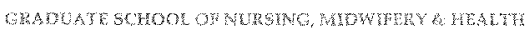

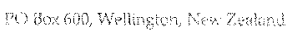

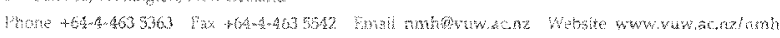




\section{Appendix E}

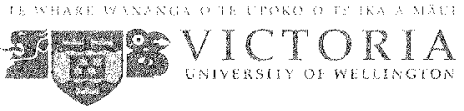

Relerase of transerint tor use

Title of Study;

An interpetative study of the coperinge of midulyes caring for wonen durine the

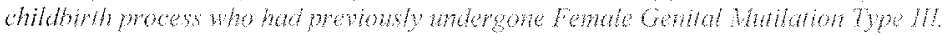

Name of participant:

Pseudonym:

Thave received the transcription of the interview and have read it. Please select one of the following options;

The transcript is acceptable as faw data povded that the conditions agreed to on the original consent form are met. I have kept the transcript because I have made no alterations.

I have amended the text of the transcript. The annotations accompany the retum of the transcript. Onee the altcrations are made, the text is agrecable as raw data provided that the conditions agred to on the originat consent form are net.

I wish to withdraw from the research study. Plcase destroy any data you have collected from me.

Signed

Date:

Please return in the enclosed self-stamped addressed envelope.

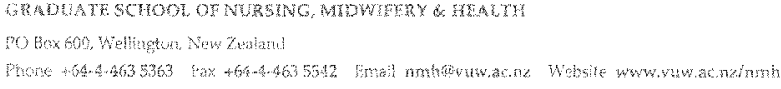




\section{Appendix F}

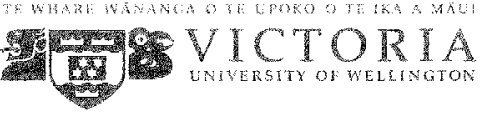

ME MDRANDUM
Whane $\quad 0 .+4-46356 \%$

Fax $\quad(1-4+4635210$

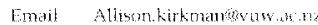

\begin{tabular}{|c|c|}
\hline TO & Annetre Garvey-Graham \\
\hline COPYTO & Or Joan Skinner \\
\hline FPOM & Dr Allison Kirkman, Convener, Human Ethics Committee \\
\hline DATE & January 16,2007 \\
\hline PAGES & 1 \\
\hline SUBJECT & $\begin{array}{l}\text { Ethics Approval: No } 148 / 2006 \text {, An inferpretive study of the } \\
\text { experience of midwives caring for women during she chilobirth } \\
\text { process, who haye undercone Female Genital Mutilation Type } \\
\text { lif. }\end{array}$ \\
\hline
\end{tabular}

Thenk you for your application for whical approval, which has now been considered by the Standing Committee of the Human Ethics Comnittee.

Your application has been approved and this approval continues until 30 August 2007. If your data collection is not completed by this date you should apply to the Human Ethics Committee for an extension to this approval.

Best wishes with the research

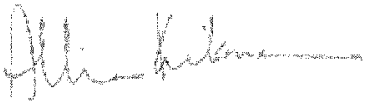

Allison Kirkman

Convener 


\section{References}

Ahmed, S. (1996). Leaving The Female Body Intact. Kai Tiaki: Nursing New Zealand, May, 20-21.

Barker, C. (1997). Cultural Relativism and Cultural Diversity: Implications for Nursing Practice. Advanced Nursing Science, 20 (1), 3-11.

Beauchamp, T.L., \& Childress, J.F. (1994). Principles of Biomedical Ethics. (4 ${ }^{\text {th }}$ ed.). Oxford: University Press, USA.

Black, J.A., \& Debelle, G.P. (1995). Female genital mutilation in Britain. British Medical Journal, 310, 1590-1592.

Bowman, J., \& Jevne, R. (2000). Ethical Evaluation in Qualitative Research. Qualitative Health Research, 10 (4), 547-554.

Bruner, J. (1986). Actual minds, possible worlds. Cambridge, MS: Harvard University Press.

Brunner, C. C. (1999). 'One’s true song': Authenticating research. In, C. Cryss Brunner, Ed.) Sacred Dreams: Women and the superintendency. (pp.177178). New York: SUNY.

Butcher, H. (1998). Crystallizing the processes of the unitary field pattern portrait research methods. Visions, 6 (1), 13-26.

Bryne, M-M. (2001). Linking philosophy, methodology, and methods in qualitative research. Association of Operating Room Nurses Journal (AORN), 73 (1), 207.

Cameron, J., \& Rawlings-Anderson, K. (2001). Genital mutilation: Human rights and cultural imperialism. British Journal of Midwifery, 9 (4), 231-235.

Chase, S. (1995). Taking narrative seriously: consequences for method and theory in interview studies R. Josselson and A. Lieblich (eds), in Interpreting Experience: The Narrative Study of Lives, vol 3, (pp. 1 - 26). Thousand Oaks, CA: Sage.

Chase, S. (2005). Narrative Inquiry: Multiple lenses, approaches, voices. In N. Denzin., \& Y. Lincoln., (Eds.). The Sage Handbook of Qualitative Research, ( $3^{\text {rd }}$ ed.), pp.651-679). California: Sage Publications.

Clandinin, D. J., \& Connelly, F. M. (2000). Narrative inquiry. Experience and story in qualitative research. (p.415) San Francisco: Jossey-Bass Publishers.

Conle, C. (2000). Narrative Inquiry research tool and medium for professional development. European Journal for Teacher Education, 23 (1), 53.

Corbin, J. \& Morse, J. (2003). The unstructured interactive interview: Issues of reciprocity and risks when dealing with sensitive topics. Qualitative Inquiry, 9 (3), 335-354. 
Cortis, J. (2004). Meeting the needs of minority ethnic patients. Journal of Advanced Nursing, 48 (1), 51-61.

Davidson, C., \& Tolich, M. (2003). Social Science Research. (2 ${ }^{\text {nd }}$ ed.). Auckland: Pearson Prentice Hall.

Dahlen, H., Nanayakkara, S., \& Bullivant, V. (1999). Female Genital Mutilation: Care of the childbearing woman. Midwifery Matter. Newsletter of N.S.W Midwives Association, 12 (6), 12-14.

Denholm, N. (1997). Female Genital Mutilation. New Zealand College of Midwives Journal, 17, 5-16.

Denholm, N. \& Jama, I. (1998). Female Genital Mutilation in New Zealand. New Zealand: FGM Education Programme.

Denzin, N. K., \& Lincoln, Y. S. (1994). Introduction: Entering the field of qualitative research. In, Norman K. Denzin \& Yvonna S. Lincoln. (eds.). Handbook of qualitative research. (pp.1-17). Thousand Oaks: Sage.

Denzin, N. K., \& Lincoln, Y. S. (2005). The Sage Handbook of Qualitative Research. (3rd ed.). (pp.656-671). Thousand Oaks: Sage.

Downie, R.S., \& Calman, K.C. (1994). Healthy respect. Oxford: Oxford Medical Publications.

Essen, B., \& Johnsdotter, S. (2004). Female Genital Mutilation in the West: traditional circumcision versus genital cosmetic surgery. Acta Obstet Gynecol Scand, 83, 611-613.

Female Genital Mutilation. Retrieved November 3, 2007 from http://www.munfw.org/archieve/50th/whoz.htm.

Flint, C. (1986). Sensitive Midwifery. London: William Heinemann Medical Books.

Fraser, R. (2005). The Public Health Needs of Waikato Migrants and Refugees. Census data (2005). Hamilton, New Zealand: The report from the Migration Research Group.

Goodfellow, J. (1998). Constructing a narrative. In, Joy Higgs (Ed.). Writing qualitative research. (pp.175-187). Sydney: Hampden Press.

Graham, H. (1984). 'Surveying through stories', in C. Bell and H. Roberts (eds), Social Researching. pp.104-24. London: Routledge \& Kegan Paul.

Guba, E., \& Lincoln, Y. (2005). Paradigmatic controversies, contradictions, and emerging confluences. In N. Denzin \& Y. Lincoln (Eds.). The Sage Handbook of Qualitative Research (pp. 191 - 217). California: Sage Publications Inc. 
Guilliland, K., \& Pairman, S. (1994). The Midwifery Partnership a model for practice. New Zealand College of Midwives Journal, 16, 5-9.

Hermanowicz, J., C. (2002). 'The great interview: 25 strategies for studying people in bed', Qualitative Sociology, 25, 479-99.

Hinchman, L., P., I. \& Hinchman, S., K. (Eds). (2001). Memory, identity, community: The idea of narrative in the human sciences. Albany: State University of New York Press.

House of Commons All Party Parliamentary Group on Population (APPG) (2000) Female genital mutilation. Survey report and analysis. England: All Party Parliamentary Group on Population, Development and Reproductive Health.

Hughes, B. (2006). FGM: Custom and tradition or an abuse of human rights? British Journal of Midwifery, 14, (7), 24.

International Confederation of Midwives (1999). The vision for women and their health. Retrieved March 31, 2002 from

http://www.internationalmidwives.org/vision/htm.

James, S. (1994). Reconciling international human rights and cultural relativism: the case of female circumcision. Bioethics, 8 (1), 1-26.

James, S. (1995). Gossip, Stories and Friendships: Confidentiality in Midwifery Practice. Nursing Ethics, 2 (4), 295-302.

Johnstone, M-J. (2000). Bioethics. A nursing perspective (3 ${ }^{\text {rd }}$ ed.). (pp. 89-90). Australia: Harcourt Saunders.

Jones, J. (2000). Concern mounts over FGM. British Medical Journal, 7252 (321), 262.

Jones, S. (2000). What is a moral issue? ( $2^{\text {nd }}$ ed.). Ethics in Midwifery Practice (p.10). Mosby. London: Harcourt Publishers.

Jordan, J. (1994). Female Genital Mutilation (female circumcision). British Journal of Obstetrics and Gynaecology, 99, 345-347.

Kanitsaki, O. (1994). Cited in Johnstone, M-J. (2000). Bioethics. A nursing perspective ( ${ }^{\text {rd }}$ ed.). (pp. 141-160). Australia: Harcourt Saunders.

Kotch, T., \& Harrington, A. (1996). Implementation of a hermeneutic inquiry in nursing: philosophy, rigour and representation. Journal of Advanced Nursing, 24, 174-184.

Kotch, T. \& Harrington, A. (1998). Reconceptualizing rigour: the case for reflexivity. Journal of Advanced Nursing, 28, (4), 882-890. 
Kotch, T. (1998). Story telling: is it really research? Journal of Advanced Nursing, 28, (6), 1182-1190.

Leap, N. (1998). Fantastic Midwifery. Tales of the unexpected. NZCOM. National conference proceedings, p.3.

Leap, N. (2000). The less we do, the more we give. In: Kirkham M (ed.), The midwife-mother relationship. London: Macmillan.

Lee, B. (2007). FGM: an outmoded practice. Midwives, 10 (2), 67-68.

Leininger, M. (1978) Transcultural Nursing: Concepts, Theories and Practices. New York: John Wiley and Sons.

Leininger, M. (1984). A Comparative analysis of Transcultural Nursing and Cultural Safety. Cited in Nursing Praxis in New Zealand, 9 (1), 8.

Leininger, M. (1990). The Significance of Cultural Concepts in Nursing. Journal of Transcultural Nursing, 2(1), 52-59.

Lincoln, Y., \& Guba, E. (1985). Naturalistic Inquiry. Newbury Park, California: Sage.

Markula, P., Grant, B. C., \& Denison, J. (2001). Qualitative research and aging and physical activity: Multiple ways of knowing. Journal of Aging and Physical Activity, 9, 245-264.

MacPherson, W. (1999). The Lawrence Enquiry. HSMO: London.

McCaffrey, M., Jankowska, A., \& Gordon, H. (1995). Management of female genital mutilation: The Northwick Park Hospital Experience. British Journal of Obstetrics and Gynaecology, 102, 787-790.

McCleary, P. (1994). Female genital mutilation and childbirth: A case report. Birth, 21(4), 221-226.

Midgley, M. (1991). Can’t we make moral judgements? Bristol: The Bristol Press.

Ministry of Health (1998). Female Genital Mutilation in New Zealand. Understanding and Responding. A national education programme. A guide for Health Professionals. New Zealand: Ministry of Health

Mishler, E., G. (1986). Research Interviewing: context and narrative. Cambridge, MA: Havard University Press.

Mitchell, R.G., \& Charmaz, K. (1996). Telling tales, writing stories: postmodernist vision and realist images in ethnographic writing. Journal of Contemporary Ethnography, 25 (1), 144-166.

Momoh, C. (2005). Female Genital Mutilation. Oxford: Radcliff Publishing Ltd. 
Newman, M. (1996). Midwifery care for genitally mutilated women. Safe Motherhood: Modern Midwife, 21-22.

New Zealand College of Midwives (2005). Midwives handbook for practice. Christchurch: New Zealand College of Midwives.

New Zealand Ministry of Health. (1995). To Health Professionals. Female Genital Mutilation, 1-4.

New Zealand Statutes. Crimes Act 1961, Amendment 1996. Retrieved April 13, 2002, from Brookers Library Manager CD rom. Cambridge Library.

Oakley, A. (1981). 'Interviewing women: a contradiction in terms'. In, Helen Roberts (ed.). Doing Feminist Research. London: Routledge

Odujinrin, O. M. T., Akitoye, C. O., \& Oyediran, M.A. (1989). A study on female circumcision in Nigeria. West Afr J Med, (3), 183-92.

Parkin, J. (2001). Female genital mutilation: a midwife’s experience. British Journal of Midwifery, 9, (7) 421-424.

Polit, D.F., \& Hungler, B.,P. (1997). Essentials of nursing research: Methods, appraisal and Utilization. ( $4^{\text {th }}$ ed.). Philadephia: Lippincott.

Polkinghorne, D.E. (1995). Narrative configuration in qualitative analysis. In J. A. Hatch., \& R. Wisniewski (Eds), Life history and narrative (pp. 5-23). London: Falmer

Ramsden, I. (1995). Cultural Safety: Implementing the Concept. New Zealand College of Midwives Journal, October, 6-9.

Rawlings-Anderson, K., \& Cameron, J. (2000). Female Genital mutilation: A global perspective. British Journal of Midwifery, 8, (12), 754- 760.

Riessman, C.K. (1990). Divorce Talk; New Brunswick, NJ: Rutgers University Press.

Roberts, K., \& Taylor, B. (1998). Nursing research processes: an Australian perspective. Melbourne: Nelson ITP.

Rouzi, A.A., \& Aljhadali, E.A. (2001). The use of intrapartum deinfibulation in women with Female Genital Mutilation. International Journal of Obstetrics and Gynaecology, 108(9), 949-951.

Rymer, J., \& Momoh, C. (2005). Female Genital Mutilation. Oxford: Radcliffe Publishing Ltd. .

Sandelowski, M. (1986). The problem of rigor in qualitative research. Advances in Nursing Science, 8 (3), 27-37. 
Sandelowski, M. (1995). Focus on qualitative methods: Sample size in qualitative research. Research in Nursing \& Health, 18, 179-183.

Seidman, S. (1998). Interviewing as Qualitative Research. New York: Teacher's College Press.

Sherratt, D. (1999). International Midwifery. In Bennett, V. \& Brown, L. Myles Textbook for Midwives (13 ${ }^{\text {th }}$ ed., p.64) London: Churchill Livingstone.

Sleep, J., \& Grant, A. (1987). West Berkshire perineal management trial: three years follow up. British Medical Journal, 295, 749 - 51.

Smythe, E. (2001). From different horizons: childbirth, tradition and politics. New Zealand College of Midwives Journal, October, 34-37.

Srivastava, R. (1996). The healthcare professional's guide to clinical cultural competence. London: Mosby Elsevier.

Swanson-Kauffman, K. \& Schonwald, E. (1998). Phenomenology, in B. Sarter (ed.). Paths to knowledge, innovative research methods for nursing. New York: National League for Nursing.

Thacker, S.B., \& Bantu, H.D.(1983). Benefits and risks of episiotomy: an interpretative review of the English language literature $1860-1980$. Obstetrical Gynaecol Survey, 38(6), 322 -38.

The Concise Oxford Dictionary (1990). (8 ${ }^{\text {th }}$ ed.). Oxford: Claredon Press

The Female Genital Mutilation Act 2003. Amendment to the 1985 Act. Retrieved September 7, 2007 from http://www.hmso.gov.uk/acts/acts2003/20030031.htm.

Tobin, G. A., \& Begley, C. M. (2004). Methodological rigour within a qualitative framework. Journal of Advanced Nursing, 48 (4), 388-396.

Toubia, N. (1995). A call for global action. Female Genital Mutilation. New York: Rainbow.

Webb, E. (1995). Female genital mutilation. A world wide problem. British Journal of Sexual Medicine (November-December): 6-8.

Weber, S online. Retrieved March 3, 2007 from http://www.iirc.mcgill.ca/about.html.

World Health Organization. (1994). Maternal and child health and family planning: Traditional practices harmful to he health of women and children. World Health Assembly, Resolution WHA47.10.

World Health Organization. (1995). WHO continues its battle against female mutilation. World Press Office, Geneva. Feature No. 186. 
World Health Organization. (1996). Female Genital Mutilation. Report of a WHO technical Working Group. World Health Organization, Geneva.

WHO/UNICEF/UNFPA. (1997). Female Genital Mutilation. A joint statement. World Health Organization, Geneva.

World Health Organization. (1998). Female Genital Mutilation, an overview. World Health Organization. Geneva.

World Health Organization. (1999). Statement on Female Genital Mutilation. Geneva.

World Health Organization. (2001). A systematic review of the health complications of female genital mutilation including sequelae in childbirth.

www.who.int/reproductive-health/docs/fgm.htm. 